\title{
CINEASTAS AFRODESCENDIENTES DEL SIGLO XXI, ENTRE DIÁSPORA, TRANSNACIONALISMO Y POST-RACIALIDAD
}

Filmmakers of African descent in the xxI century, between diaspora, transnationalism and post-racialityd

\author{
LEONARDO DE FrANCESCHI ${ }^{\mathrm{a}}$ \\ Università Roma Tre. Dipartimento Filosofia Comunicazione e Spettacolo \\ DOI: http://dx.doi.org/10.15366/secuencias2015.41.004
}

\section{RESUMEN}

En los últimos quince años (2001-14), el cine diaspórico afrodescendiente ha crecido, aunque haya sido a través de modalidades diferentes, según los diferentes contextos nacionales. El creciente éxito de estrellas como Denzel Washington, Idris Elba o Omar Sy, junto a la irrupción en los Oscars de 2014 del director Steve McQueen, está facilitando el desarrollo de un nicho de público transnacional, formado sobre todo por jóvenes afrodescendientes cada vez más conscientes y deseosos de verse representados por personajes negros en papeles importantes. De Estados Unidos a Europa, estamos asistiendo al surgimiento de una sensibilidad más proactiva, flexible y pragmática por parte de directores afrodescendientes, que se mueven con distintas estrategias de política identitaria y de relación con la industria, pero con los mismos objetivos de empoderamiento. La referencia a la agenda nacional e identitaria, cuando está presente de una forma marcada, sí que tiende a construir una relación privilegiada con un público de referencia afrodescendiente, pero apuesta también por influir en el imaginario y el mercado mainstream. Llama la atención el intento de algunos de deshacerse de la hipoteca de un peso de la representación que sigue afectando a directores afrodescendientes, con la complicidad de una crítica cinematográfica que sigue interpretando la experiencia de los directores afrodiaspóricos desde una perspectiva discontinuista, excepcionalista, como expresión de una «comunidad imaginada», además, cada vez más difícil de circunscribir. Lo que me propongo es recorrer, de manera no sistemática, el trayecto que han realizado las personalidades afrodescendientes más significativas que emergieron o se confirmaron en el panorama cinematográfico durante el período examinado, con atención especial a Francia, Gran Bretaña y Estados Unidos.

Palabras clave: Cine, diáspora, África, transnacionalismo, post-racialidad, afropolitanismo, afrodescendientes

\begin{abstract}
In the last fifteen years (2001-14), the afro-descendant diasporic film has grown, albeit different modes of the different national contexts. The rising success of stars like Denzel Washington, Idris Elba and Omar Sy, together with the award of an Oscar in 2014 to the director Steve McQueen, have allowed the development of a transnational public formed mostly by young afro-descendants that are ever more conscious and willing to see themselves represented by black characters in key roles. From the United States to Europe, we are witnessing the emergence of a more proactive, flexible and pragmatic sensibility on the part of afro-descendant directors that work with different identity politics strategies and different ways of relating to the industry, but with the same objective of empowerment. Reference to national and identity agendas, when made visible, certainly does tend to construct a privileged relationship with an afro-descendant public, but it is also intended to influence the social imaginary and the mainstream market. The effort that some go to in order to remove the burden of representation that still affects afro-descendant directors is noteworthy, as is the complicity of a cinematographic critique that continues to interpret the experience of afro-diasporic directors from a non-continuist, exceptionalist perspective, as an expression of an «imagined community» that is ever more difficult to circumscribe. My aim here is to review, in a non-systematic way, the journey undertaken by the most significant afro-descendant personalities that have emerged or were consolidated in the cinematographic panorama during the period under review, with particular attention to the cases of France, the United Kingdom and the United States.
\end{abstract}

Keywords: Film, diaspora, Africa, Transnationalism, Post-racionality, Afro-politanism, Afro-descendants

[a] Leonardo de Francheschi enseña Cine Postcolonial y Media Studies en la Universidad Roma Tre. Su investigación se centra en la imagen de África y de las diásporas en el cine, y en la experiencia de los realizadores africanos o afrodescendientes. En términos más generales, trabaja en la reconfiguración de un campo de estudio focalizado en el cine y los medios de comunicación, vistos a través de lo poscolonial, en un marco transnacional/traslacional, prestando atención a cuestiones de raza, género y clase. Sobre estos temas, ha escrito muchos artículos para antologías y revistas (Africa e Mediterraneo, afriche e orienti, Bianco e Nero, CinemAction, Cinergie, Close-Up, Eidos,Imago, Iperstoria, Parole chiave, Quaderni del CSCI, Sentieri selvaggi, The Postcolonialis) y cuatro monografías, la última de las cuales es L'Africa in Italia: Per una controstoria postcoloniale del cinema italiano (Roma: Aracne editrice, 2013). Dirige una colección de libros para la editorial Aracne, codirige el sitio web en italiano Cinemafrica (cinemafrica.org) y el blog Cinemafrodiscendente (cinemafrodiscendente.com). 
Abrir un espacio de reflexión sobre la producción cinematográfica afrodiaspórica significa interrogarse de forma preventiva sobre la epistemología y la metodología a utilizar ${ }^{1}$. La primera opción tiene que ver con el periodo que voy a examinar: con el objetivo de establecer un horizonte temporal lo más homogéneo posible, he decidido dedicarme a la producción de los últimos quince años (2001-14), usando como terminus ante quem el año del 11 de septiembre, no solo y no tanto por el impacto que este evento ha tenido en las dinámicas de las relaciones entre el norte y el sur global, cuanto por las recaídas que ha producido en la esfera cinematográfica, como explicaré mejor más adelante. En este lapso temporal, el debate alrededor de conceptos cruciales de la contemporaneidad como la globalización, la multiculturalidad y el transnacionalismo ha vuelto, en parte, a poner en discusión una disposición de saberes que maduraron en los primeros años noventa, justo después de otro hecho histórico como la caída del muro de Berlín. Naturalmente, este no es el sitio para dar cuenta de la complejidad de este debate; me contentaré mencionando algunos aspectos que han tenido una particular relevancia para el cine, entendido en el doble horizonte pragmático y teórico-crítico.

Mi representación de este debate, sintomática y orientada, obedece a un enfoque discursivo, según la acepción que utilizan Will Higbee y Song Hwee $\mathrm{Lim}^{2}$. Me dispongo a releer este proceso de revisión epistemológica que ha tenido lugar en estos últimos quince años sobre la base de un interés específico que me ha llevado desde hace años a trabajar, desde mi ámbito disciplinar, los film studies, y desde mi país de nacimiento y residencia, Italia, con vistas a la consolidación de un horizonte de estudios postcoloniales sobre el cine y los medios de comunicación, y a la luz de dos reflexiones, producidas en dos ambientes y dos momentos históricos diferentes, pero que en mi opinión van en la misma dirección.

La primera viene del antropólogo crítico Jean-Loup Amselle, que insiste de forma particular en la necesidad de superar la así llamada razón etnológica en el análisis de los hechos sociales, sobre la base de una perspectiva continuista o mestiza $^{3}$. Esta perspectiva teórica, que vuelve a definir sobre bases antropológicas una difusa orientación antiesencialista presente en los estudios críticos florecidos a partir del pensamiento post-estructuralista, me induce a desconfiar de muchos intentos que se han hecho, a lo largo de los años, para definir y circunscribir en términos excluyentes el horizonte de las producciones culturales diaspóricas.

La segunda reflexión, en cambio, tiene que ver con los film studies y en particular con los estudios sobre «cine africano» (las comillas son obligatorias tratándose de un concepto muy forzado y construido históricamente); proviene del estudioso canadiense Alexie Tcheuyap y gira en torno a su interés por las narraciones fílmicas postnacionalistas que han surgido como reacción contra un orden discursivo dominante en la producción y en el debate crítico-teórico que ha caracterizado al «cine africano»: un orden discursivo atrincherado en la valoración exclusiva de directores «que han predicado sobre un deseo entendi-
[1] Agradezco la invitación a participar en número monográfico a mi amigo Fernando González, al cual me une, además del interés y la pasión por las cinematografías del sur del mundo, la común amistad por el llorado Alberto Elena. A la querida memoria de Alberto está dedicado el presente ensayo. Un agradecimiento también a Lidia Merás, que ha seguido el trabajo de redacción.

[2] Will Higbee, Song Hwee Lim, «Concepts of Transnational Cinema: Towards a Critical Transnationalism in Film Studies» (Transnational Cinemas, vol. 1, $\left.\mathrm{n}^{\circ} 1,2010\right)$, p. 9.

[3] Jean-Loup Amselle, «Chapitre premier: La raison ethnologique» en Logiques métisses. Anthropologie de l'identité en Afrique et ailleurs (Paris, Payot, 1990), pp. 15-44. Soy conscien te del hecho de que mi intento de recuperar las categorías de Amselle desde una perspectiva hermenéutica postcolonial, fuerza de manera considerable el enfoque total del pensamiento del autor. 
ble de definir África por oposición al "occidente" unificado, una búsqueda de un "ser africano" ontológico, una ansiedad genuina sobre una historia perdida y una identidad amenazada»4. Este cortocircuito entre ámbito creativo y receptivo, con los años, ha marginado toda experiencia y todo intento de interpretación que prescindiesen de la centralidad del peso de la representación, una especie de reedición asimétrica del white man's burden de Kipling, que obliga a directores (y artistas en general) africanos y afrodescendientes a responder al repertorio de estereotipos y mensajes alienantes lanzados por el cine mainstream sobre África y sus sujetos diaspóricos, imponiendo una visión auténtica y popular de África y sus comunidades, y a moverse en un registro rigurosamente realista ${ }^{5}$. El contrapunto perfecto de este síndrome, eminentemente postcolonial y postracial (en el sentido que se precisará mejor más adelante), está representado por la recurrente tendencia a leer cada producción del «cine africano» o diaspórico como alegoría o expresión de alguna identidad colectiva superior, (trans)nacional.

[4] Alexie Tcheuyap, «Introduction», en Postnationalist African Cinemas (Manchester, Manchester University Press, 2011), p. 10.

[5] Kobena Mercer, «Black Art and the Burden of Representation" (Third Text, vol. $4, \mathrm{n}^{\circ} 10$, 1990), pp. 61-78; Ella, Shohat, Robert Stam, Unthinking Eurocentrism. Multiculturalism and the Media (New York/London, Routledge, 1994), pp. 182-188.

[6] Ato Quayson, Girish Das wani, «Introduction - Diaspora and Transnationalism: Scapes, Scales, and Scopes», en Ato Quayson, Girish Daswani (dir.), A Companion to Diaspora and Transnationalism (Malden/Oxford/Chicester, Wiley-Blackwell, 2013), p. 7.

[7] Laura Marks, The Skin of Film: Intercultural Cinema, Embodiment, and the Senses (Durham/London, Duke University Press, 2000).

[8] Hamid Naficy, An Accented Cinema: Exilic and Diasporic Filmmaking (Princeton, NJ/ Oxford, Princeton University Press, 2001).

\section{Tres palabras clave y una opción de método}

1) Diáspora. Ato Quayson y Girish Daswani han examinado muy oportunamente la serie de etapas que han marcado la apropiación de este concepto clave en el ámbito discursivo de la comunidad afroamericana y, más en general, afrodescendiente ${ }^{6}$. Al mismo tiempo que durante estos años, hacia finales del siglo pasado, se consolidaba una subdisciplina académica específica, los diaspora studies. Los estudiosos han intentado circunscribir y definir la experiencia diaspórica, distinguiéndola, por un lado, de la del exilio, y, por otro, de la de las minorías étnicas o culturales. Esta lógica se ha hecho notar también en los estudios dedicados a las producciones cinematográficas, donde en el primer caso, el elemento discriminatorio se había encontrado con la opción entre la identificación del sujeto del discurso en una perspectiva individual versus colectiva, mientras que en el segundo, la alternativa estaba entre la proyección ideal hacia un territorio de origen y la relación, más o menos problemática, con el de residencia. Como alternativa a este binarismo artificial e inservible si se quiere hacer un análisis de textos y contextos, han surgido dos textos seminales a caballo entre los dos siglos: The Skin of Film de Laura Marks ${ }^{7}$ y An Accented Cinema de Hamid Naficy ${ }^{8}$.

Estos dos ensayos, utilizando marcos teóricos que en algunos aspectos pueden superponerse, han propuesto una serie de constantes productivas y estilísticas adscribibles a las producciones fílmicas diaspóricas y transnacionales, definidas por la primera como «interculturales» y por el segundo como «acentuadas»: el énfasis se ha puesto, por un lado, en el carácter intersticial de los modos de producción, al margen de las lógicas industriales del mercado, y por el otro, sobre una estética basada en la centralidad del cuerpo como vector de emociones y memorias irreproducibles. 
Sin embargo, vistos a través de una lente continuista y postnacionalista, los dos textos presentan, paradójicamente, el límite de hacer demasiado énfasis sobre una perspectiva que pretende definir en sentido exclusivo el cine diaspórico y transnacional, «ubicado en los márgenes de las culturas fílmicas dominantes o en las periferias de las prácticas industriales, haciendo casi imposible evaluar el impacto que tales películas puedan tener en el mainstream o en los cines populares ya sea dentro de un contexto nacional o transnacional» ${ }^{9}$.

Pese a ser consciente de los riesgos de las definiciones, Michael T. Martin, algunos años antes, había publicado una importante antología de textos críticos, en cuya introducción, pese a afirmar que «la filmación de películas en la diáspora negra no es un proyecto unificado o monolítico», terminaba por sintetizar su visión del cine diaspórico negro, «primero, como un proceso de producción fílmica, independiente y comercial, preocupado por temas negros donde la gente de linaje africano participa como guionista, director $\mathrm{y} / \mathrm{o}$ productor. $\mathrm{Y}$ segundo, como una orientación política y una práctica cultural de oposición ${ }^{10}$. Por tanto, se vuelve, exportándola a un contexto transnacional, a la competición denunciada por Tcheuyap entre directores y críticos para ver quién es más realista que el rey, para ver quién es capaz de llegar a una práctica y a una definición más rigurosas del «cine africano». Además, la experiencia del cine diaspórico ha seguido siendo, también desde el punto de vista del léxico, constantemente racializada, como si no existiese una producción relevante por parte de directores expatriados u originarios de países del norte de África o de la Sudáfrica blanca post-Apartheid.

2) Pero vayamos al término transnacionalismo. Quayton y Daswani nos recuerdan que este término fue utilizado por primera vez en el lejano $1916^{11}$, entrando en el léxico simbólico colectivo únicamente en los primeros años noventa. Pese a haber sido utilizado de forma intercambiable con el de diáspora, el concepto de transnacionalismo tiende a ser considerado como una expansión del primero, en el sentido de hacer visible una presencia de posibles factores de coalición que supera el horizonte comunitario: «como categoría analítica, las comunidades transnacionales son entendidas como diásporas superadas, porque tales comunidades pueden no derivar principal o exclusivamente de formas de identificación cultural o co-étnica que son constitutivas de las diásporas, sino de modos opcionales de identificación que incluyen clase, sexualidad e intereses profesionales ${ }^{12}$.

Además, según Quayson y Daswani, otro matiz de significado puede encontrarse en esa especie de modelo bipolar que domina el léxico diaspórico, que da importancia a las relaciones que conectan al sujeto del discurso con el país de origen y de residencia, mientras que el léxico transnacionalista subraya la presencia de corrientes multilocales y policéntricas ${ }^{13}$ que superan, cuantitativamente y cualitativamente, el esquema simbólico de los diaspora studies. No en vano, estos están todavía ligados, en algunos aspectos, a un binarismo anticolonial y a una experiencia de la trayectoria migratoria como viaje solo de ida.
[9] Will Higbee, Song Hwee Lim, «Concepts of Transnational Cinema», p. 10.

[10] Michael T. Martin, «Framing the 'Black' in Black Diasporic Cinemas», en Michael T. Martin (dir.), Cinemas of Black Diaspora. Diversity, Dependence and Oppositionality (Detroit, Wayne State University Press, 1995), p. 3.

[11] Ato Quayson, Girish Das wani, «Introduction - Diaspora and Transnationalism», p. 12.

[12] Ato Quayson, Girish Daswani, «Introduction - Diaspora and Transnationalism», p. 4.

[13] Arjun Appadurai, «Disjuncture and Difference in the Global Cultural Economy», en Modernity at Large: Cultural Dimensions of Globalization (Minneapolis, University of Minnesota Press, 1996), p. 33. 
[14] Will Higbee, Song Hwee Lim, «Concepts of Transnational Cinema», p. 18.

[15] Will Higbee, Song Hwee Lim, «Concepts of Transnational Cinema», p. 18.

[16] Para profundizar en el debate véase Mark Ledwidge, Kevern Verney, Inderjeet Parmar (dir.), Barack Obama and the Myth of a Post-Racial America (New York and London, Routledge, 2013), Michael Tessler, David O. Sears, Obama's Race: The 2008 Election and the Dream of a Post-Racial America (Chicago, The University of Chicago Press, 2008).

[17] Cfr. Eduardo Bonilla Silva, Racism without Racists: ColorBlind Racism and the Persistence of Racial Inequality in America, $4^{\text {th }}$ ed., (Plymouth, Rowman \& Littlefield Publishers, 2013), Dennis Delippe, Protesting Affirmative Action: The Struggle over Equality after the Civil Rights Revolution (Baltimore, The Johns Hopkins University Press, 2012).

[18] Véase por ejemplo Ella Shohat, Robert Stam, Race in Translation: Culture Wars around the Postcolonial Atlan tic (New York and London, New York University Press, 2012).
La línea, bastante reciente, de los estudios transnacionales de cine, inaugurada virtualmente por el citado ensayo de Higbee y Lim, extrae su planteamiento de un transnacionalismo crítico que, programáticamente, «no aísla la producción fílmica transnacional en intersticios o espacios marginales, sino que interroga sobre cómo estas actividades de realización fílmica negocian con lo nacional en todos los niveles» ${ }^{14}$; y en relación con el público, se propone «examinar la capacidad de las audiencias locales, globales y diaspóricas para decodificar películas mientras circulan de manera transnacional (...), construyendo una variedad de significados que van de la adaptación y la asimilación a lecturas más desafiantes o subversivas de estas películas transnacionales» ${ }^{15}$. Esta perspectiva analítica, como veremos, nos será muy útil para entender la red de conexiones que enlaza de forma fáctica o que pone en común virtualmente distintas expresiones fílmicas de la diáspora africana.

3) Postracialidad. También este discutido término será evocado de una forma alusiva y acaso también superficial. Me refiero evidentemente al debate que ha tenido lugar en Estados Unidos desde noviembre de 2008, cuando llegó al poder el primer presidente de fenotipo no caucásico. Este debate ha puesto sobre la mesa la cuestión del estatus presuntamente postracial alcanzado por el sistema-país después de la elección de Barack Obama ${ }^{16}$, avivando de nuevo una serie de discusiones sobre los discutibles efectos del color o race blindness ${ }^{17}$. Han sido necesarios los disturbios de Ferguson, Missouri, en agosto del 2014, y otros hechos de resonancia todavía más recientes, como el homicidio de Eric Garner, para que los medios de comunicación volviesen a prestar atención al racial profiling habitual de la policía en las metrópolis estadounidenses y el intolerable white privilege que todavía marca el destino para los ciudadanos White Anglo-Saxon Protestant de nacimiento.

Por otro lado, las discusiones sobre la persistencia de la raza como constructo social y discursivo plenamente operativo en la orientación del debate público, en las prácticas políticas y en las producciones artísticas a los dos lados del Atlántico negro, continúan incendiando la escena académica, volviendo a proponer antiguas contraposiciones y problemas de traducción cultural en la interpretación de los conflictos sociopolíticos internos, por ejemplo entre Francia y Estados Unidos ${ }^{18}$.

Este debate también ha tenido repercusiones en la escena cinema-

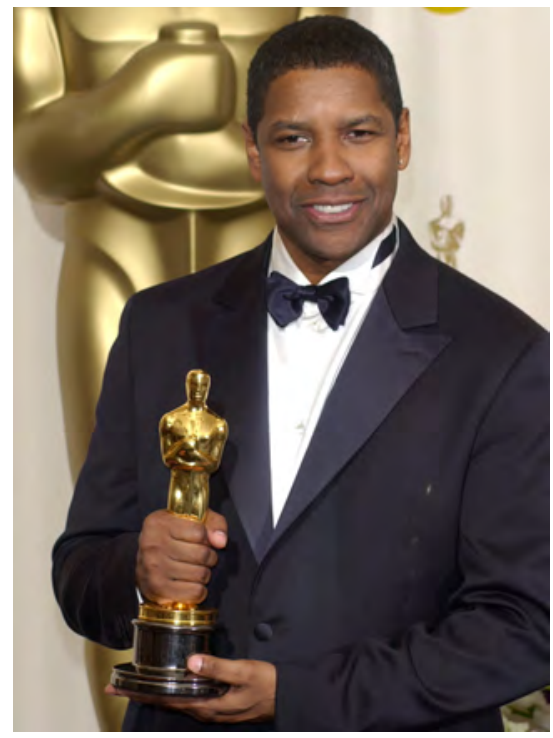

Denzel Washington, con uno de los dos Oscar de la Academia conseguidos. 
tográfica global, en concomitancia con algunos momentos de una fuerte carga simbólica, como en los Premios de la Academia de Hollywood con la estatuilla a la mejor interpretación para actores muy populares como Denzel Washington (2001) y Halle Berry (2002), el ascenso de Will Smith al estatus de estrella post-black ${ }^{19}$, la aparición sobre el escenario de jóvenes autores afroamericanos independientes como Lee Daniels impulsados por el Festival de Sundance (Precious es de 2009), el reciente éxito de público obtenido por películas de temática vinculada a la raza como The Blind Side - Un sueño imposible (The Blind Side, John Lee Hancock, 200920) o Criadas y señoras (The Help, Tate Taylor, 201121) y por el neofilón de slave movies inaugurado por Quentin Tarantino con Django desencadenado (Django Unchained, 2012) y retomado por el Black British Steve McQueen con 12 años de esclavitud (Twelve Years a Slave, 2013).

Dentro de Europa, un escenario parecido, salvando las distancias, se ha planteado en Francia, aunque es verdad que, por un lado, el mercado ha visto emerger potentemente vedettes de origen inmigrante como Omar Sy e Dany Boon $^{22}$, y por otro, también la crítica y la red de festivales de serie A han consagrado el ascenso de directores postmigrantes como Rachid Bouchareb ${ }^{23}$ y Abdellatif Kechiche ${ }^{24}$. Tuvo también un gran eco la entrega, por parte del Festival de Cannes, del premio como mejor actor al elenco de Días de gloria (Indigènes/Days of Glory, Rachid Bouchareb) en 2006, que comprendía a intérpretes de origen franco-magrebí del calibre de Amel Debbouze, Samy Naceri, Roschdy Zem y Sami Bouajila.

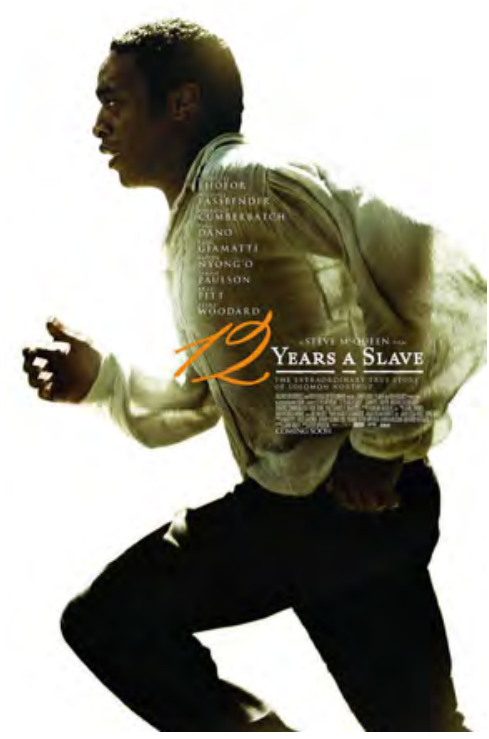

Cartel original de 12 años de Esclavitud (12 Years a Slave, Steve McQueen, 2013).

[19] Entre el 2007 y el 2008, Soy leyenda (Francis Lawrence, 2007) y Hancock (Peter Berg, 2008) superan ambas la barrera de los doscientos millones de dólares de ganancias solo en el mercado interno (256 y 227 millones de dólares, respectivamente), acercándose a los cuatrocientos millones en el extranjero (328 y 396 millones de dólares), y al récord alcanzado en los años noventa por Independence Day (Roland Emmerich, 1996), con 306 y 511 millones de dólares. Fuente (para este y el resto de datos posteriores): Box Office Mojo <http: //www.boxofficemojo.com>.

[2o] The Blind Side obtuvo, respectivamente, 255 y $53 \mathrm{mi}-$ llones de dólares en los mercados local y mundial.

[21] Criadas y señoras, con un presupuesto de veinticinco millones de dólares, se llevó a casa algo así como 169 y 46 millones de dólares, respectivamente en los mercados local y mundial.

[22] Nacido en Trappes, de madre mauritana y de padre senegalés, Sy ha sido coprotagonista de Intocable (Intouchables, Eric Toledano, Olivier Nakache, 2008) vista, solo en Francia, por casi veinte millones de espectadores (19.440.920), ganando 420 millones de dólares a escala mundial. Por su parte, Dany Boon, nacido en Armentières, en el norte de Francia, de padre argelino-cabilio y madre ch'ti, es el director e intérprete, junto al franco-argelino Kad Merad de Bienvenidos al Norte (Bienvenue chez les Ch'tis, 2007) que ha obtenido un total de más de veinte millones de espectadores (20.489.303) en Francia, rozando los 250 millones de dólares de ingresos en todo el mundo (245.144.417). Fuentes: Box Office Mojo <http://www. boxofficemojo.com> y Wikipédia France <https://fr.wikipedia.org/wiki/Liste_des_plus_gros_succès_du_box-office_en_France>.

[23] Rachid Bouchareb, nacido en París en 1959, de padres argelinos, ha sido seleccionado a concurso varias veces en el Festival de Berlín (Little Senegal, 2001; London River, 2009; La voie de l'ennemi, 2014) y en Cannes (Días de Gloria, 2006; Fuera de la ley [Hors la loi], 2010).

[24] Nacido en Túnez en 1960 pero llegado a Niza con solo seis años, Adellatif Kechiche fue promocionado por el Festival de Venecia, donde su debut La culpa la tiene Voltaire (La Faute à Voltaire) ganó en 2000 el Premio Luigi De Laurentiis a la mejor opera prima; también en Venecia se presentaron Cuscús (La graine et le mulet, León de Oro, 2007) y Venus negra (Venus noire, 2010), mientras que la última y aclamada La vida de Adèle ha conseguido más de ochenta premios, a partir de la Palma de Oro en Cannes. 
[25] Me refiero por ejemplo al caso de Intocable, recibido con una frialdad mucho mayor en Estados Unidos que en Francia por parte de la crítica, que reconoció en el personaje de Omar Sy algunos rasgos y una práctica performativa en la línea de estereotipos de la peor tradición hollywoodiense. Veáse, por ejemplo, las críticas de Variety (http://variety.com/ 2011/film/reviews/untouchable -1117946269/) y Hollywood Reporter (http://www.hollywoodre porter.com/movie/intouchables -france/review/240178).

[26] Gerald Sim, The Subject of Film and Race: Retheorizing Politics, Ideology, and Cinema (New York/London/New Delhi, Sidney, Bloomsbury Academic, 2014), p. 1.

[27] Miguel Mellino, La critica postcoloniale. Decolonizzazione, capitalismo e cosmopolitismo nei postcolonial studies, (Ro ma, Meltemi, 2005), pp. 19-27.

[28] En L'Africa in Italia. Per una controstoria postcoloniale del cinema italiano (Roma, Aracne editrice, 2013), he analizado, junto a otros estudiosos, la contribución aportada por los cineastas afrodescendientes al cine italiano, desde el mudo hasta hoy, convencido de que el cine, práctica eminentemente colaborativa e industrial, tiene que estudiarse superando una visión excesivamente focalizada en el papel del director-autor. En este caso, he adoptado el término «afrodescendientes» en una acepción todavía más inclusiva, comprendiendo directoras y directores africanos de origen pero también de nacimiento. El trabajo de monitorización y reflexión continuará en el blog Cinemafrodiscendente (cine mafrodiscendente.com), actualmente en un estado avanzado de desarrollo.
Sería interesante, desde el punto de vista del debate crítico, releer paralelamente los análisis producidos por parte de observadores privilegiados de la escena afrodiaspórica global durante estos años, como Olivier Barlet y Tambay Obenson en sus muy seguidas e influyentes cabeceras on line, de las respectivas Africultures (africultures.com) y Shadow and Act (blogs.indiewire.com/shadowandact), para valorar las dinámicas específicas de recepción de las películas citadas, pero también de los filmes, eminentemente transculturales, que tienen que ver con intentos de conquistar el mercado extranjero ${ }^{25}$.

Con respecto a algunas de las películas citadas (The Blind Side, Precious, Criadas y señoras y Django desencadenado), Gerald Sim observa como «las reseñas fílmicas y los comentarios sociales que generan, demuestran que la raza continúa siendo un tema de disputa. La cultura fílmica es un foro prominente para ese debate público. Su audiencia parece poseer una conciencia entusiasta de la presencia ideológica en las películas, dentro del estereotipo pero también más allá» ${ }^{26}$.

Estas consideraciones pueden explicar las razones por las cuales sostengo, desde hace tiempo, que el patrimonio de experiencias y saberes interpretativos asociados al binomio raza y cine producido en Estados Unidos representa un inestimable bagaje para todo proyecto de fundación de una crítica de orientación multiculturalista radical y postcolonial. Pero aclaran también por qué considero que es útil leer las producciones fílmicas diaspóricas a través de una lente postracial, sugiriendo una utilización paradójica - no literaria sino metafórica- del prefijo «post», en la línea de lo que sugiere el antropólogo Miguel Mellino cuando se refiere al término postcolonial ${ }^{27}$, para así no ocultar, sino hacer visibles, las conexiones entre pasado y presente.

4) Y cerramos esta sección de reflexiones epistemológicas con algunas puntualizaciones ulteriores sobre mis opciones de método. Aunque en el texto haya hecho referencia, por razones pragmáticas, al cine diaspórico negro o africano, en la línea de una cierta tradición de estudios de origen nacionalista, considero más productivo revisar el posicionamiento de los directores, juntándolos en el horizonte léxico del origen afrodescendiente ${ }^{28}$. Los identifico como afrodescendientes en cuanto que considero que el término presenta una cierta incompatibilidad con las lógicas esencialistas de una razón racializada, no continuista y nacionalista ${ }^{29}$.

Tomando postura en contra de algunas clasificaciones que, a mi parecer, son excesivamente excluyentes, cuando hablo de directores afrodescendientes reconozco en este horizonte discursivo un continuum que comprende, en masculino y en femenino: a) directores expatriados, que trabajan fuera del conti-

[29] Muy en uso sobre todo en América Latina hispanófona y lusófona entre cuantos se reconocen descendientes de las víctimas de la trata atlántica y por tanto inicialmente adoptado para definir a los sujetos afrolatinos, el término ha sido reconocido como expresión de una amplia red de movimientos de base, que se llevan luchando desde el 2000 para que la noción fuese adoptada para definir a todos los sujetos y pueblos de las diáspora africana, propuesta que fue recibida por la Naciones Unidas ya en la conferencia de Durban en 2001. 
nente pero nacieron en un país africano; b) directores de segunda generación, al menos uno de cuyos progenitores es de origen africano; c) directores diaspóricos, ubicables en comunidades vinculadas con África por procesos de migración históricos, más o menos forzados. Especifico además que, independientemente del espacio que les dedicaré en este artículo, considero parte de esta gran familia afrodescendiente a todas y todos los directores activos en una práctica audiovisual narrativa o paranarrativa reconducible a las tres tipologías señaladas, independientemente del hecho de que sean habitualmente enmarcados en el cine diaspórico negro, o a otros horizontes discursivos, por el mercado, la crítica y el circuito de los festivales.

Por meras razones de espacio, además de por coherencia del corpus de textos, estaré obligado a limitar mi mirada a directoras y directores que han realizado largometrajes de ficción, dejando fuera a las y los que están prevalentemente orientados, en cambio, hacia otros formatos expresivos en el ámbito de la ficción, desde el cortometraje hasta la serie, o hacia creaciones que se pueden inscribir en el horizonte de la no-ficción, desde las varias acepciones del cine documental hasta las prácticas incluidas en el videoarte.

Soy, por último, consciente del carácter parcial y deliberadamente no exhaustivo de mi enfoque histórico: algunos vacíos, así como rápidos resúmenes sirven para recordar que cada narración, pese a que esté argumentada, obedece siempre a criterios refutables; por otra parte, como nos recordaba Foucault, «el saber no se hace para comprender, se hace para resolver»30.

\section{Algunas consideraciones de conjunto}

Uno de los conceptos más recurrentes para definir a artistas e intelectuales africanos, de origen o de nacimiento, que se mueven ya en una perspectiva transnacional, es el de «afropolitanismo», introducido originariamente por la escritora y fotógrafa Taiye Selasi ${ }^{31}$, y retomado por el filósofo Achille Mbembe, en relación con «la entrada de África en una nueva era de dispersión y de circulación» que:

se caracteriza por la intensificación de las migraciones y por la implantación de nuevas diásporas africanas en el mundo. Con la emergencia de estas nuevas diásporas, África ya no constituye un centro en sí. A partir de ahora está hecha de polos entre los cuales hay un constante paso, circulación y caminos abiertos. [...] La conciencia de esta imbricación del aquí y del allá, la presencia del allá en el aquí y viceversa, esta relativización de las raíces y de las pertenencias primarias y esta manera de abrazar, con todo conocimiento de causa, lo extraño, lo extranjero y lo distante, esta capacidad de reconocer su cara en el rostro del extranjero y de valorar las huellas de lo lejano en lo cercano, de domesticar lo siniestro, de [3o] Michel Foucault, «Nietzche, la généalogie, l'histoire», en AA.VV., Hommage à Jean Hyppolite (Paris, Presses Universitaires de France, 1971), p. 160.

[31] Taiye Selasi, «Bye-Bye Babar» (The Lip, 3 March 2005), $<$ http://thelip.robertsharp.co. $\mathrm{uk} / \mathrm{p}=76>$. 
[32] Achille Mbembe, Sortir de la longue nuit. Essai sur l'Afrique décolonisée (Paris, Éditions La Découverte, 2013), pp. 224, 229. Hay que decir, de paso, que el término, de alguna manera contrapuesto al de panafricanismo, se lo ha apropiado la industria cultural postcolonial como una etiqueta de fácil aplicación a toda clase de productos culturales, tanto que críticos y escritores también cercanos a esta categoría comodín, como Adichie y Wainiana, se están distanciando de ella.

[33] Vanessa Lanari lo hizo en una ponencia para el congreso Africa en movimento/Africa on the Move (Macerata, 1720/9/2014), <http://cirafrica. unimc.it/it/convegno-asai/panel1/5_Lanari_Afropolitaninelcine maafricano_ASAI_2014.pdf>.

[34] Veáse: Alessandro Jedlo wski, Nollywood. L'industria video nigeriana e le sue dira mazioni (Napoli, Liguori, in corso di pubblicazione); Matthias Krings, Onokoome Okome (dir.), Global Nollywood. The Transnational Dimensions of an African Video Film Industry (Indiana University Press, Bloomington, 2013). Ver también el artículo de Alejandra Val $\mathrm{Cu}$ bero incluido en el presente monográfico, pp. 41-56. trabajar con lo que parece opuesto; es esa sensibilidad cultural, histórica y estética la que muestra bien el término "afropolitanismo"»32.

Curiosamente, son todavía pocos los que están intentando aplicar este horizonte conceptual al cine ${ }^{33}$, a lo mejor precisamente porque es paradójicamente difícil circunscribirlo a un ámbito restringido y reconocible de directores. Basta con pensar, por ejemplo, en el hecho de que, a causa de la sustancial carencia de infraestructuras para la formación, la producción y la postproducción -con la parcial excepción de cinematografías históricamente más estructuradas sobre el plano industrial (Egipto y Sudáfrica)-, desde los años sesenta, las directoras y directores africanos están en su mayoría obligados a formarse, buscar financiación para sus propias películas y proveerse de los equipos técnicos y establecimientos de postproducción en países del Norte global, por lo general entre Europa y Norteamérica, activando, de hecho, modalidades eminentemente transnacionales de economía del cine. Muchos de ellos se han visto echando raíces en París, Londres o Bruselas, desarrollando un vertiginoso vaivén entre su país de origen y su(s) país(es) de acogida. Cuando este dinamismo transnacional ha conseguido socios para la coproducción, fondos internacionales y contratos de preventa con emisores, se ha llegado a ver con cierta regularidad cómo una

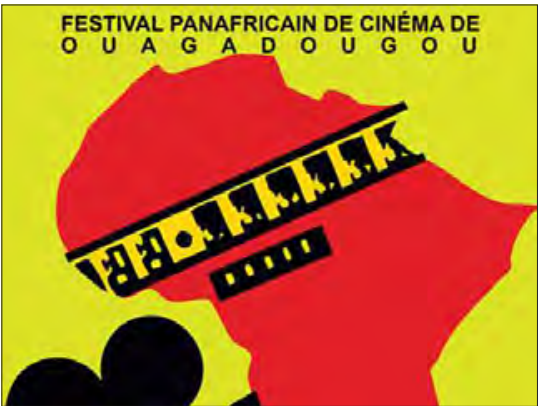

Festival Panafricain de Cinéma de Ouagadougou (FESPACO). película se distribuye a partir de acuerdos concretos en los mercados nacionales correspondientes, pero se trata de dinámicas que no han aumentado todavía en modo significativo el mercado de este cine afropolitano transnacional.

Otro modelo diferente, más intersticial y sumergido, vinculado a las posibilidades ofrecidas por las redes diaspóricas transnacionales que sostienen a las comunidades nigerianas y ghanesas expatriadas, ha hecho emerger en estos últimos años películas de bajo presupuesto, rodadas, antes en vídeo analógico y ahora en digital, por exponentes de estas comunidades que residen en el extranjero. Son dirigidas tanto al público de las diásporas como al de origen, y distribuidas a través de circuitos de economía informal que hacen de sustento a empresarios de import/export y a través de la web ${ }^{34}$.

La red de los festivales de cine africano, panafricano y diaspórico ha promovido y consolidado con los años el conocimiento de directoras y directores africanos de origen a través de distintos contextos. El histórico FESPACO (Festival Panafricain du Cinéma de Ouagadougou), fundado en 1969 y que llega ya a su vigésimo tercera edición, creó en 1989 el Prix Paul Robeson, destinado a la 
mejor película de la diáspora. Con la parcial excepción de Lumumba, una coproducción Francia-Bélgica-Alemania-Haití dirigida por el haitiano Raoul Peck, premiada en 2001, ninguna de las películas que han obtenido el Paul Robeson ha conseguido alcanzar una distribución comercial internacional, probablemente porque la mayor parte de los reconocimientos han ido, con la excepción de la estadounidense Lisa Gay Hamilton (premiada en 2005 por el documental Beah: A Black Woman Speaks), a directores caribeños poco conocidos en el mercado global, como el haitiano Arnold Antonin (premiado tres veces seguidas en 2007, 2009 y 2011) o la martiniquesa Mariette Monpierre (premiada en 2013 por Le bonheur de Elza)

En Europa, vale la pena señalar una cita de referencia como el Black International Cinema de Berlín (blackinternationalcinema.de), instituido en 1986 y transformado en una kermesse competitiva en 1991. En el ámbito estadounidense, hay que recordar el valioso trabajo realizado por el Pan African Film Festival de Los Ángeles (PAFF: paff.org), activo desde 1992, el African Diaspora Film Festival de Nueva York (ADFF: nyadiff.org), fundado en 1993 y que pertenece a la etiqueta ArtMattan (africanfilm.com), y por el American Black Film Festival (ABFF: abff.com), inaugurado en 1997, también con sede en Nueva York, solo por citar los festivales más focalizados en el cine diaspórico internacional.

Sin embargo, hay que constatar que el impacto de estas iniciativas ha tenido un débil efecto sobre el mercado, y que el horizonte conceptual del Estado-nación sigue teniendo su relevancia en lo referente a la distribución y la exhibición. No son muchos las directoras y los directores que tienen la posibilidad de ver, con cierta regularidad, sus propias películas introducidas en el circuito global de la distribución de pago (salas de cine, homevideo, televisión, web): Lee Daniels, Antoine Fuqua, Allen y Albert Hughes, Spike Lee, John Singleton; el inglés Steve McQueen; y el francés Dany Boon. Verdaderos hijos predilectos para el público local como el estadounidense Tyler Perry son relativamente desconocidos en otros mercados.

Probablemente internet y, quizás, las televisiones de pago podrán a medio y largo plazo producir una virtuosa dinámica de reacercamiento entre las distintas audiencias afrodescendientes locales, favoreciendo procesos de estrellato y autoría transnacionales. Con todo, no me consta que existan actualmente, por ejemplo, portales VOD dirigidos específicamente a un público afrodiaspórico ${ }^{35}$, pero creo que se trata de una nueva frontera que el mercado audiovisual global debería tener mucho interés en explorar.

\section{Europa}

Razonando desde una perspectiva comparada, solo en Francia y en Gran Bretaña, y precisamente en estos quince últimos años, podríamos decir que se está cumpliendo esa especie de círculo virtuoso que ha llevado desde la emergencia
[35] El portal sudafricano Afri cafilms.tv (http://www.africa films.tv) todavía no ha atraído un número consistente de productos dirigidos por directores afrodiaspóricos, pero podría hacer de útil pionero en este sentido. 
de un filón sobre los temas de la inmigración hasta el encumbramiento de directores postmigrantes en la escena internacional, pasando por la llegada de una primera ola de producciones diaspóricas (el cinéma beur en Francia, el Black British Cinema en Reino Unido).

1) En Francia, conviven directores de primera y segunda generación en el rico tejido del cine afrodescendiente, algunos activos incluso desde los años sesenta, como Med Hondo (último trabajo: Fatima, l'Algerienne de Dakar, 2004). Para el argelino Mahmoud Zemmouri (1946-), que vive en Francia ya desde la segunda mitad de los años setenta, las primeras décadas del segundo milenio han sido difíciles y poco productivas -ha realizado solo dos largometra-

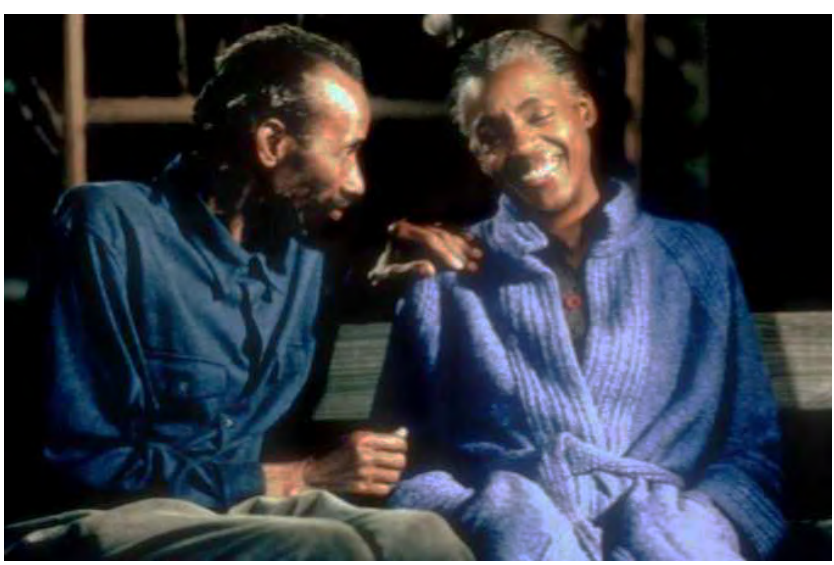

Alloume (Sotigui Kouyate) e Ida (Sharon Hope) en Little Senegal (Rachid Bouchareb, 2001). jes: Beur blanc rouge en 2006, ocho años después del anterior; y la reciente Certifiée halal (2014)-, mientras que el coterráneo y casi coetáneo Merk Allouache (1944-), más atento a mantener con vida las relaciones de producción con su país de origen, ha firmado ya once títulos entre largometrajes y $t v$ movies entre los cuales hay un auténtico blockbuster: Chouchou, (2003) ${ }^{36}$ y dos títulos muy bien valorados por la crítica como Harragas (2009) y Es-stouh (2013), presentada a concurso en la Mostra de Venecia. Para Abdelkrim Bahloul (1950-, en Francia desde 1971), Mehdi Charef (1952-, en Francia desde 1962), Karim Dridi (nacido en 1961 en Tunez, activo en Francia desde 1987) y Malik Chibane (1964-), los mosqueteros del cinéma beur, que explotó en la segunda mitad de los ochenta, han sido también años complicados: algunos de ellos (Bahloul con Le soleil assassiné, en 2003, en Venecia; Charef con Cartouches gaulois, en 2007, en Cannes; Dridi con Khamsa, en 2008, en Locarno) han tenido la oportunidad de presentar sus películas en plazas importantes; o, como Dridi con El último vuelo (Le dernier vol, 2009), la posibilidad de tener a su disposición un presupuesto considerable (veinticuatro millones de dólares) y una estrella internacional (Marion Cotillard). Pero los resultados han sido inferiores a las expectativas.

La consagración ha llegado, en cambio, para dos talentos, hijos también ellos de los cruciales años ochenta, como Rachid Bouchareb y Abdellatif Kechi-

[36] La película facturó casi treinta y tres millones de euros (32.950.862) en 2003, y la vieron 3.876.572 personas, acabando sexta en la clasificación general del año, segunda entre las francesas después de Taxi 3 (Gérard Krawczyk, 2003). che. El primero empezó a recoger resultados de una carrera de ya casi treinta años (el debut, Baton rouge, es de 1985) precisamente en 2001, cuando su Little Senegal se presentó a concurso en la Berlinale: con la excepción de Just Like a Woman (2012), todos sus largometrajes se han presentado a concurso en un festival de serie A, lo que confirma su entrada en el restringido grupo de directores a tener en cuenta. Bouchareb tiene, por su parte, varios puntos fuer- 
tes: subrayaría de manera particular su capacidad para escribir guiones compactos al estilo clásico, calibrados sobre personajes sólidos y reconocibles con la capacidad de dotar de valor a actores afrodescendientes y a los que no lo son, y también su aptitud para montar su propia productora (la 3B Productions, fundada en 1989). Además, tiene el talento para construir películas que, ya sea en el plano de la política cultural o en el de los modelos estilísticos, se dirigen de igual manera tanto hacia una integración europea (pienso sobre todo en London River, sobre el luto de la comunidad inglesa y franco-diaspórica tras los atentados de Londres en 2005), como hacia el diálogo con la tradición y el imaginario ya sea hollywoodiense o indy (en este sentido el camino ya empieza con Bâton rouge y llega hasta dos películas «americanas», Just Like a Woman y La voie de l'ennemi, pasando por la citada Little Senegal). Podríamos decir que, en cierto sentido, Bouchareb es el director francés más en primera línea en lo que atañe a la construcción de un nicho de mercado afrodescendiente transnacional.

Por su parte, Abdellatif Kechiche, después de una primera etapa como actor destacado del cinéma beur (protagonizó Le thé à la menthe, Abdelkrim Bahloul, 1984), se estrena como director-autor con la multipremiada La culpa la tiene Voltaire (La Faute à Voltaire, 200o), ganando -por primera vez absoluta para un director de origen franco-magrebí- el César por su dirección en $L a$ escurridiza (L'Esquive, 2005).

De ahí en adelante Cannes y Venecia se han disputado cada uno de sus nuevos títulos al son de los premios, consagrándolo definitivamente con la Palma de Oro por La vida de Adèle (La vie d'Adèle, 2013). Kechiche es portador de una poética, respecto a la de Bouchareb, aparentemente aún más en la línea maestra del cine africano nacionalista. En realidad, Kechiche acepta el reto con argumentos y elenco transnacionales, y con cuestiones que pueden parecer externas a la agenda de los emigrantes o postmigrantes (la experiencia LGTB). Pero sobre todo persigue una investigación estilística rigurosamente modernista, en busca de un naturalismo radical, a partir de un estilo de rodaje a la altura del intérprete e implicando al espectador sobre todo me diante el juego con la performatividad de los cuerpos de los actores.

En la vertiente autoral, durante estos quince años han surgido otros dos directores, de orígenes y edades distintas, pero unidos por un modelo de producción muy distintivo, es decir, por trabajar de una forma independiente, sosteniendo su propia productora y con bajos presupuestos. El mayor es Rabah

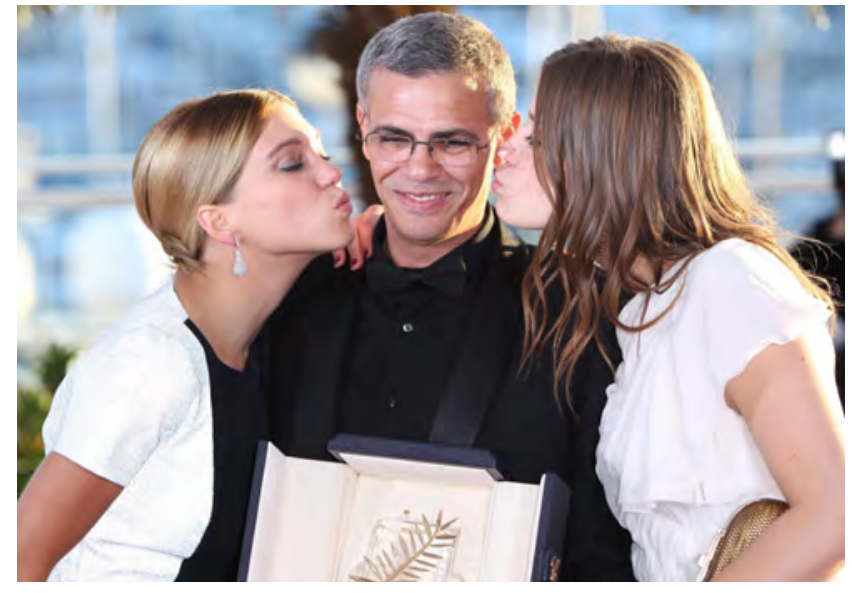

Abdellatif Kechiche con la Palma de Oro por La vida de Adèle (La vie d'Adèle, 2013). 
Ameur-Zaïméche (nacido en 1966 en Argelia, pero ya en Francia dos años después), que se estrena como director en 2001 con Wesh wesh, qu'est qui ce passe? (Prix Louis Delluc a la ópera prima) y que en el arco de quince años realiza otras tres películas, presentadas con éxito en Cannes y Locarno, pasando de un drama sobre la exclusión social ambientado en la cité des Bosquets en SaintDenis, a una película histórica sobre la vida de un popular bandido del siglo xviII (Les Chants du Mandrin, 2011), e imponiéndose con un estilo «de baja intensidad», hecho de un naturalismo minimalista y extrañador con tintes surreales y una sutil ironía. Quince años más joven, Djnn Carrénard (nacido en Haití en 1981 y afincado en Francia desde 1998), al final de un complicado periplo entre Togo, Guyana y Estados Unidos, hace su debut con Donoma (2011), un film de guerrilla de presupuesto irrisorio (ila nota de prensa hablaba de ciento cincuenta euros!), realizado sin un equipo profesional (Carrénard se ocupa él solo de guion, fotografía, montaje y sonido). El film, seleccionado en Cannes por el ACID, se convierte en una verdadera obra de culto, seguida por el menos ambicioso FLA (2014): las dos películas, la primera más coral, la segunda con una estructura de tres personajes, insisten en una trama de dramaturgia densa y llena de complejas problemáticas, que contrasta con una escritura visual muy nerviosa y agresiva.

Rachid Djaidani (nacido en 1974, de padre argelino y madre sudanesa) también llega al cine después de un recorrido absolutamente personal e independiente. Como Ameur-Zaïméche, él también viene de una cité, y después de una breve carrera como boxeador, inicia un camino paralelo como escritor y cineasta, empezando como actor en cine, televisión y teatro (cinco años con Peter Brook), y debutando como director en 2012 con la apreciada y amarga Rengaine, seleccionada para la Quinzaine des Réalisateurs, lo que le vale una nominación a los César como mejor ópera prima.

Los tres nombres que estoy a punto de escribir pertenecen, en cambio, a la nutrida subfamilia de los cineastas afrodescendientes de origen subsahariano, afropolitanos por destino y convicción, y descubiertos en este lapso temporal. Newton I. Aduaka (oriundo de la región nigeriana del Biafra y nacido en 1966, poco antes del estallido de la guerra), ya en 1985 se encaminó en una dirección diaspórica sin retorno, primero a Londres (donde estudia en la London International Film School y rueda Rage, su primera película), y después a París, ciudad a la que se muda y donde vive hoy en día. En estos quince años realiza unas de las películas de referencia del «cine africano» del nuevo milenio, Ezra, seleccionada en Cannes y en Sundance, premiada en el FESPACO 2007, ensayo de ejemplar libertad compositiva y prodigiosa construcción a partir de una amalgama de profesionales y no profesionales sobre un tema de riesgo como es la condición de los niños soldado. Emile Abossolo-Mbo empieza a ser finalmente valorado, junto a la siempre profunda Aïssa Maïga, por una película de cámara mucho más intimista (One Man's Band, 2012), en la cual un actor de mediana edad se enfrenta a las tres mujeres de su vida cuando la noticia de un tumor le obliga a hacer cuentas con sus propios límites. Aduaka ha presentado 
en Cannes y en Roma el proyecto de un nuevo largometraje (Oil on Water, de la novela de Helon Habila) sobre la miserable guerra que acontece en el delta del Níger, pero, también en este caso, todo hace suponer que su mirada estará filtrada por su retórica fílmica, que se sostiene a través de una narración no lineal y una utilización extrañadora de la música.

Alain Gomis (nacido en 1972, de padre senegalés y madre francesa) ha debutado precisamente en 2001 con L'Afrance (Pardo d'Argento en Locarno), siendo consagrado entre los mejores autores afrodescendientes en activo con Aujourd'hui (presentada en 2012 a

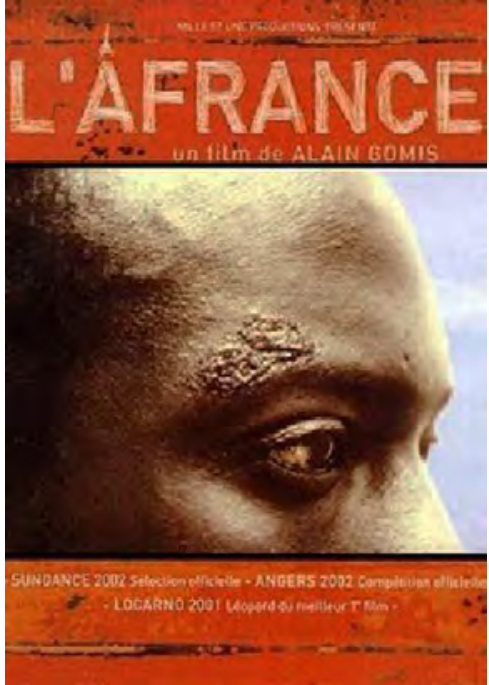

Cartel de L'Afrance (Alain Gomis, 2001). concurso en la Berlinale y ganadora del

Etalon de Yennenga en FESPACO 2013): inmigración, alienación, búsqueda de sentido, las películas de Gomis tocan temas universales en ciertos aspectos, que, sin embargo, declina cuando recupera precisos modelos afrocéntricos (Fanon, Lumumba, Kane y Hondo en L'Afrance) pero aprendiendo a alejarse rápidamente de ellos, para englobar puntos de vista excéntricos, como el de un joven banlieusard de orígenes argelinos obsesionado con Andalucía (Andalucia, 2007), o el de un más maduro senegalés que vuelve de Estados Unidos y se despierta sabiendo que va a vivir el último día de su vida (en Aujourd'hui, producida por la Granit, que funda con Aduaka).

Dyana Gaye (nacida en 1975, de padre senegalés y madre italiana) llegó al largometraje en 2013 con Des étoiles, después de un aprendizaje de más de diez años, en el curso de los cuales realizó cuatro cortos muy apreciados en los festivales. Presentado como preestreno mundial en Toronto, el debut de Gaye presenta varias ingenuidades en el plano de la verosimilitud, pero enlaza tres historias de migración y búsqueda de la felicidad entre Dakar, Nueva York y Turín, reflejando con eficacia la condición de toda una generación de jóvenes africanos cada vez más dispuestos a apostar por su futuro en un horizonte de posibilidades virtualmente inmenso.

Historias en femenino, moduladas por una mirada intimista que cruza razones personales y colectivas, llegan de otra cineasta afrodescendiente como Karin Albou (nacida en Francia, de padres franco-argelinos) autora de, por ahora, solo dos largometrajes, La petite Jerusalem (2004) y La canción de las novias (Le chant des mariées, 2008), muy bien valorados por la crítica por su capacidad de reflejar la mirada de algunas adolescentes que deben de afrontar pequeñas y grandes decisiones sobre su futuro, dentro de un contexto dominado por el peso de las tradiciones. 


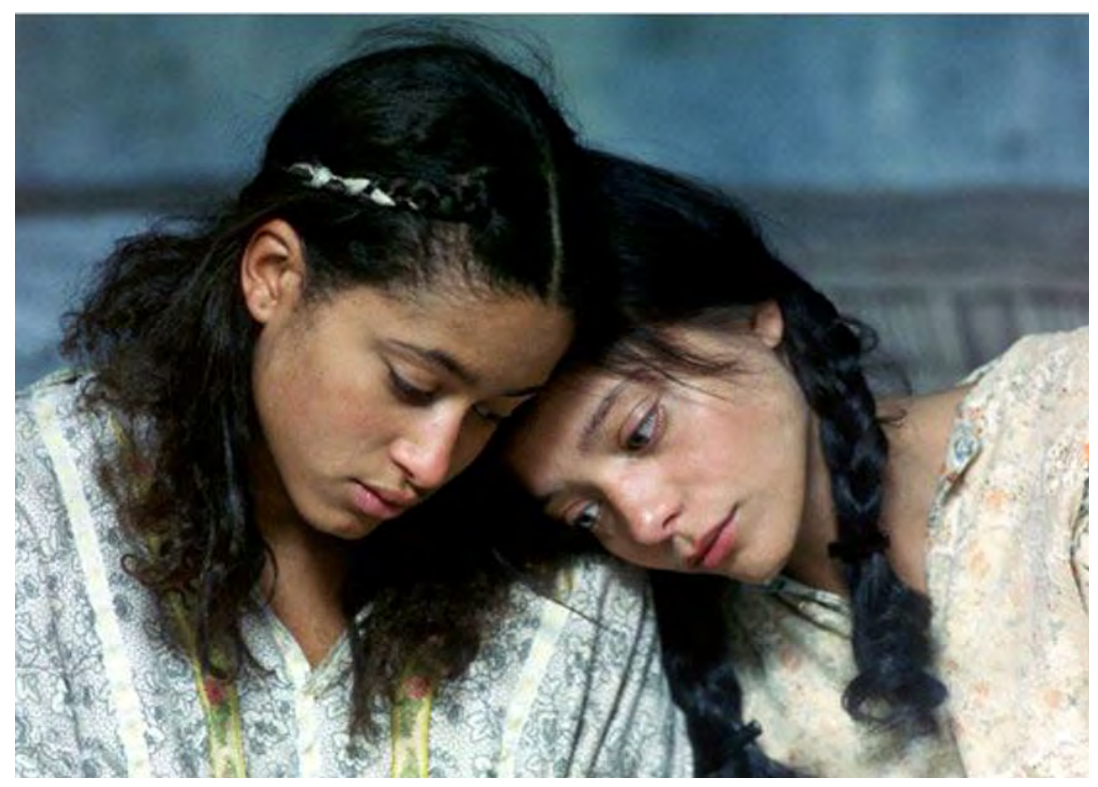

Lizzie Brocheré y Olympe Borval el La canción de las novias (Le chant des mariées, Karin Albou, 2008).

El nuevo milenio en Francia se recordará también como la época del surgimiento de una nueva generación de actores y directores afrodescendientes que crecieron entre la pequeña pantalla y el escenario. El más amado, también más allá de las fronteras, es seguramente Dany Boon. Con solo cuatro películas realizadas hasta ahora como director (frente a veintidós solo como intérprete), la segunda de las cuales, Bienvenidos al Norte (Bienvenue chez les Ch'tis, 2007), lo reveló como actor poliédrico y director brioso, se trata, sin embargo, de un talento discontinuo, puesto que los dos títulos siguientes Nada que declarar (Rien à declarer, 2011; más de ocho millones de espectadores) y, sobre todo, Hypercondriaque (2014, más de cinco millones) solo han repetido parte del éxito de público de la segunda.

Muy lejos de estos resultados, nos encontramos con Case départ (2012), discutida comedia de enredo ambientada en una plantación esclavista del siglo XVIII, dirigida e interpretada por el dúo cómico conformado por Thomas Ngijol y Fabrice Eboué, dos treintañeros de origen camerunés, que quedó séptima entre los títulos franceses del año, con cerca de un millón ochocientos mil espectadores. Otros favoritos del público transalpino, desde Gad Elmaleh hasta Kad Merad, han intentado también el camino de la dirección, aunque con resultados muy inferiores a las expectativas.

Quedándonos en el territorio del cine de género, vale la pena señalar un recorrido a contracorriente, transnacional y postnacionalista, como el de Mabrouk El Mechri (nacido en 1976, de padres de origen tunecino), que, estrenándose en 2005 con Virgil, insólita y pequeña película de boxeo producida por la Gaumont con Jalil Lespert, construye su segunda obra sobre la biografía 
de Jean Claude Van Damme, JCVD (2008). Después del intervalo de una serie francesa para Canal Plus, llega incluso a realizar un thriller de acción independiente en los Estados Unidos, Cold Light of the Day (2012).

2) Si se considera la vivacidad de la escena artística afroinglesa en los años ochenta y noventa, dominada por el fervor de los grupos Black Audio Film Collective (1982-98) y Sankofa (1983-92), así como por el debate crítico promovido por estudiosos como Stuart Hall, Koben Mercer y Coco Fusco, y si se tiene en cuenta el agotamiento de experiencias relevantes como la revista Black Filmmaker Magazine (1998-2008) y el BFM International Film Festival con sede en Londres (1998-2010) ${ }^{37}$ llevadas a cabo por Menelik Shabazz, es posible que el cuadro actual aparezca como menos estructurado. Hay que reconocer que el sistema-país ha puesto igualmente sobre la mesa varias iniciativas para mejorar las posibilidades de acceso al mercado para los talentos afrodescendientes en los ultimísimos años: aquí me limito a citar la exposición fotográfica Want to See More of $M e{ }^{3{ }^{3}}$, realizada en 2009 por el fotógrafo Donald MacLellan en colaboración con el UK Film Council. La exposición mostraba numerosos retratos, sobre todo de actores y actrices Black British, algunos definitivamente consagrados como estrellas transnacionales justo en estos ultimísimos años, desde Chiwetel Ejiofor a David Oyelowo. En 2011, la crítica y promotora Nadia Denton publicó The Black British Filmmaker's Guide to Success, un instrumento muy útil que reúne observaciones y entrevistas que cubren todo el espectro de la maquinaria cinematográfica ${ }^{39}$, seguido en septiembre del 2014 por un nuevo volumen dedicado esta vez a Nollywood. Por último, en noviembre del 2012, la periodista freelance Akua Gyamfi lanzó su portal The British Blacklist (thebritishblacklist.com), el cual presenta informaciones y artículos en profundidad sobre la actividad de los talentos afroingleses activos en el mundo del showbusiness (en particular el cine, la televisión, el teatro y la literatura).

Si se considera que la primera película de un director Black British distribuida comercialmente en salas fue Burning an Illusion (1981), obra del ya citado director originario de las Barbados, Menelik Shabazz, que volvió a la dirección solo en 2011 con un documental sobre un género pop que estuvo de moda durante los años ochenta (The Story of Lovers Rock) ${ }^{40}$, es posible comprobar la persistencia de una notable dificultad para los directores afrobritánicos no tanto para rodar su primera película, como para encontrar su público y
[37] En la fase de revisión del texto, me ha llegado la feliz noticia de la vuelta del BFMIFF, programado en Londres del 2 al 5 de julio de 2015 .

[38] «Donald MacLellan's portraits of black actors", (The Guardian, 23 February 2009), <http://www.theguardian.com/ artanddesign/gallery/2009/feb /23/photography-theatre>.

[39] El volumen se puede descargar de forma gratuita en la siguiente url: <http://www. nadiadenton.com/books/black -british-filmmakers-guidesuccess $>$.

[40] En enero del 2015, la se gunda película de Shabazz (con el título provisional de Looking for Love) está todavía en post producción y se está financiando a través de una campaña de crowdfunding en la web Indiegogo (https://www.indiegogo.com/ projects/looking-for-love--2\#/). 


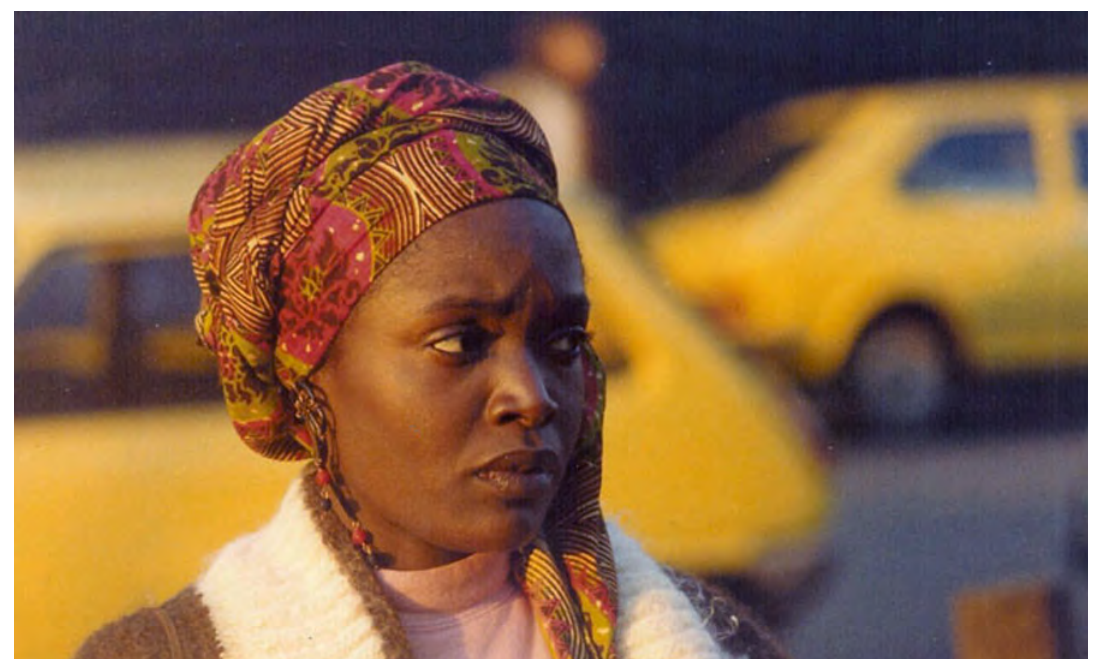

Cassie McFarlane en Burning an illusion (Menelik Shabazz, 1981).

trabajar con una cierta continuidad. La base de datos The British Blacklist contiene fichas de hasta cuarenta y ocho directores afroingleses, muchos de los cuales proceden de excolonias británicas, treinta y dos hombres y dieciséis mujeres. De estos, sin embargo, solo trece han conseguido realizar un largometraje de ficción en el lapso temporal aquí analizado, y para seis de ellos (Julius Amedume, Destiny Ekaragha, Jesse Lawrence, Leon Herbert y Debbie Tucker Green) se trata por ahora del único. La mayor parte de ellos, a veces o por lo general, intérpretes (Richard Ayoade, dos títulos; Noel Clarke, tres títulos; además del citado Herbert), trabajan con presupuestos reducidos y pequeñas productoras independientes, encontrándose con dificultades para distribuir e incluso tan solo para presentar sus propias películas fuera del territorio nacional.

Algunos han tenido, en cambio, la posibilidad de ser lanzados en importantes festivales: Amma Asante (nacida en 1969, de padres ghaneses), después de una etapa como actriz sobre todo televisiva, vio como en 2004 y 2013, respectivamente, se presentaban sus dos largometrajes en Toronto. Mientras el primero (el drama social A Way of Life, ambientado en Cardiff) se estrenó después únicamente en Gran Bretaña, el segundo (Belle) participó en varios festivales estadounidenses, consiguiendo importantes reconocimientos y llegando a numerosos mercados, tantos que consiguió más de dieciséis millones de dólares en ingresos globales. Quizá fue por efecto del éxito transnacional de 12 Años de Esclavitud, ya que también en este caso el guion está inspirado en la verdadera historia de una chica, hija ilegítima de una esclava negra y de un aristócrata en la Inglaterra del siglo xvıII, y sobrina de un juez encargado de deliberar en un juicio crucial para el futuro de la esclavitud en el Reino Unido. 
Richard Ayoade (nacido en 1977, de padre nigeriano), parecía destinado a un ascenso fulgurante después de su debut con la comedia Submarine (2010), producida por Ben Stiller, acogida con un consenso considerable por parte de la crítica en Toronto y distribuida en varios mercados. Pero el thriller The Double (2013), inspirado en El Doble de Dostoievski, a pesar de que el elenco era de primer nivel, y se presentó también en Toronto, Londres, Tokio y otros festivales muy respetables, decepcionó en parte las expectativas puestas en ella.

La base de datos se olvida, curiosamente, de dos nombres emergentes. Sobre todo, de la prometedora Sally El Hosaini, de padre egipcio, cuyo único largometraje realizado hasta ahora (My Brother the Devil, 2012), acerca de la relación entre dos hermanos British Arabs en la frontera de la edad adulta, el descubrimiento de la sexualidad y las desviaciones sociales, ha sido multimpremiado por la crítica británica y la americana en Sundance, en la Berlinale y en el London Film Festival. Todavía más reciente es la primera experiencia en el cine del novelista y comediógrafo Biyi Bandele, nacido en Nigera en 1967, pero residente en Londres desde 1990, que en la edición del 2013 del Festival de Toronto presentó en preestreno mundial una adaptación del bestseller Half of a Yellow Sun de Adichie, coproducción anglonigeriana, interpretada por las estrellas Black British transnacionales Chjiwetel Ejiofor y Thandie Newton, y que fue recibida tibiamente por la prensa americana.

De lo que no hay duda es de que la verdadera punta de lanza surgida en la escena afroinglesa de estos quince años es Steve McQueen, de cuarenta y cinco años, nacido a las afueras de Londres, de padre de Granada y madre de Trinidad. En realidad, el director ha recogido en estos años los frutos de una actividad de más de veinte años de investigación y experimentación sobre soportes, lenguajes y fórmulas narrativas, que en los años noventa, después de una formación en artes visuales en el Chelsea College of Art and Design, en el Goldsmith College y en la Tisch School of the Arts de Nueva York, tomó forma sobre todo en cortometrajes e instalaciones destinadas a museos y galerías, y le valió la consecución del prestigioso Premio Turner. El debut llega en 2008 con Hunger, película sobre la incansable lucha en prisión llevada a cabo por Bobby Sands y otros miembros del IRA para obtener el estatus de presos políticos: seleccionada en Cannes en la sección Un Certain Regard, y premio Camara d’Or. En Shame (2011), realizada con un presupuesto más importante y presentada a concurso en el festival de Venecia, se reencuentra con su actor fetiche, Michael Fassbender, premiado con la Coppa Volpi por la mejor interpretación masculina, en el papel de un hombre obsesionado por una sexualidad compulsiva y alienante: la película logra un más que discreto favor del público, consiguiendo en taquilla más de diecisiete millones de dólares, de los cuales solo cuatro fueron en Estados Unidos. Quiero hacer notar que con ambas películas McQueen se coloca con valentía fuera de una lógica nacionalista, en el primer caso, afrontando un tema y un personaje centrales para la historia británica del siglo xx; en el segundo, arriesgando con una historia de fuertes implicaciones universales. Ya en Shame, McQueen había introducido un personaje afrodes- 
cendiente decisivo, a su manera, en la economía de la trama: Marianne. Pero el viraje que prepara lo va a consagrar como autor de relevancia del cine contemporáneo, posicionándolo en un espacio reconocible también por parte del público negro. Me refiero naturalmente a la elección de las memorias de Solomon Northrup, 12 Años de esclavitud, que le vale un importante éxito en taquilla (casi ciento ochenta y ocho millones de dólares de recaudación total, de los cuales más de cincuenta y seis fueron en Estados Unidos) y sobre todo una impresionante serie de reconocimientos, desde los Globos de Oro (mejor película dramática), pasando por los BAFTA (mejor película y mejor protagonista para Chiwetel Ejiofor), hasta los Premios de la Academia de Hollywood, en los que se premió al guionista John Ridley, a la intérprete no protagonista Lupita Nyong'o y al equipo de producción, incluido McQueen, con la estatuilla a la mejor película del año, honor jamás concedido a un director afrodescendiente hasta ese momento. McQueen, que realiza una puesta en escena de tendencias extrañadoras, centrada en el cuerpo como lugar de negociación privilegiado del sujeto en lo que atañe a las relaciones de fuerza entre individuo y sociedad, y en una escritura visual tan modernista en lo sintáctico como formalista en lo compositivo, forma parte de una generación de cineastas Black British, como Ejiofor, Elba y Newton que, manteniendo elevada la dignidad del oficio y con la mirada fija en el horizonte del mercado, están contribuyendo de manera importante a la consolidación de un público transnacional negro y, más en general, afrodescendiente, y, consecuentemente, al refuerzo del poder contractual de los cineastas negros en el propio Hollywood.

3) En el resto de países europeos, la presencia de una comunidad diaspórica de asentamiento más reciente y menos ligada a la herencia de las ex potencias coloniales, y la menor capacidad de la industria nacional para dar espacio a talentos de origen emigrante, ha hecho más difícil la aparición no tanto de figuras singulares de directores, como de un potencial movimiento de cineastas afrodescendientes.

En Bélgica, o mejor dicho en un constante ir y venir entre Bruselas y Kinshasa, su ciudad natal, vive un director afropolitano por antonomasia como Balufu Bakupa-Kanyinda (nacido en 1957), que por razones de formación, trabajo y enseñanza ha pasado largos períodos también en Francia, Gran Bretaña y Estados Unidos. Autor de diversos cortometrajes y documentales multipremiados, en 2007 firmó su primer y hasta ahora único largometraje, Juju factory, sobre las vivencias de un escritor congoleño exiliado en Bruselas, al que su editor encarga una especie de guía turística de Matonge, una zona de la ciudad con mucha población inmigrante.

En el país están también en activo varios directores de segunda generación y origen marroquí. Mourad Boucif, nacido en el 1967 en Argelia, de padres marroquíes que enseguida se trasladaron a Bélgica, ha trabajado durante mucho tiempo como educador en organizaciones interesadas en favorecer la integración o tutelar los derechos negados de migrantes de diferentes generaciones. Los dos largometrajes de ficción que ha realizado reflejan esta sensibili- 
dad social: Au-delà de Gibraltar, realizado en 2001 y codirigido con Taylan Barman, sobre los problemas de integración de la juventud de origen migrante, y Les larmes d'argent, de 2007, sobre la sangre vertida por las tropas de extracción colonial durante la segunda guerra mundial.

Ismaël Saidi (1976-) ha realizado en los quince años que estamos examinando numerosos cortos y películas de tono brillante para la televisión, entre los cuales se incluye la afortunada serie Rhimou, muy apreciada en Marruecos. Dos son los largometrajes que ha dirigido hasta ahora: el biopic histórico Ahmed Gassiaux (2010) sobre las experiencias de un marroquí adoptado por un oficial del ejército colonial francés, y la brillante comedia Moroccan gigolos (2013).

Ha suscitado cierto entusiasmo el debut de Nabil Ben Yadir (1979-) de padres marroquíes, con la comedia amarga Les barons, de coproducción franco-belga (2009, sobre las peripecias de un pequeño grupo de vitelloni de segunda generación, que oscilan entre el parasitismo social y la integración alienante. Su segunda obra, La marche (2013), relectura personal de la histórica Marcha por la igualdad y contra el racismo del 1983, no convenció, a pesar de que el casting incluye nombres queridos por el público francófono como Jamel Debbouze, Olivier Gourmet y Hafsia Herzi, y el aval de personalidades de primer plano de la escena política francesa. Muy reciente y apreciado, en cambio, ha sido el debut a cuatro manos de dos directores nacidos en 1988, Adil El Arbi y Bilall Fallah, con el thriller Image (2014), sobre las experiencias de una periodista encargada de hacer un reportaje en las periferias de Bruselas, que se deja arrastrar por un joven marroquí.

En Suiza, Holanda e Italia viven desde hace varias décadas tres directores argelinos de nacimiento, nacidos en 1949 y crecidos en los terribles años de la guerra de liberación. En Suiza desde 1972, Mohammed Soudani, diplomado en el IDHEC de París y activo también como director de fotografía, ha realizado cinco largometrajes, cuatro de los cuales entre 2007 y 2014, rodados mayoritariamente en la Suiza italiana y caracterizados por un cierto eclecticismo en la elección de los géneros. En Holanda desde 1989, Karim Traïdia se dio a conocer con su ópera prima (De Poolse bruid, 1998), una historia de amor e inmigración clandestina premiada en Roterdam. Activo también en el ámbito televisivo, Traïdia realizó la adaptación de una novela contemporánea, Eilandgasten (2005) y está ultimando una película histórica de sabor autobiográfico, ambientada durante la guerra de liberación (Chroniques de mon village). En Italia desde mediados de los años noventa, Rachid Benhadj ha dirigido varios documentales y dos largometrajes en el período que nos interesa, moviéndose por diferentes países del Mediterráneo: El khoubz el hafi (2005) es una adaptación personal de una de las más aclamadas novelas de la literatura árabe del siglo xx, obra del marroquí Mohammed Choukri, ambientada en el Marruecos de los años sesenta; Parfums d'Alger (2013) marca en cambio su vuelta a Argelia después del terrible período de la guerra civil, narrado a través de una fotógrafa crecida en Francia que se ve obligada a 
[41] Más particular fue la carrera llevada a cabo por el brillante actor afroalemán Pierre Sanoussi-Blis (nacido en 1962 en Berlín, hijo de un diplomático guineano y una profesora de la ex RDA), conocido por el gran público por su participación en una serie de televisión de éxito como Der Alte y en decenas de papeles (también gracias a Doris Dörrie en Nadie me quiere [Keiner liebt mich, 1994]). Es autor además de una buena comedia (Zurüch auf Los!, 2000) sobre los temas del amor y de la solidaridad en la comunidad LGTB.

[42] Son varios los estudios críticos dedicados a esta producción. Señalo particularmente Isabel Santaolalla, Los «Otros». Etnicidad $y$ «raza» en el cine español contemporáneo (Zaragoza/Madrid, Prensas Universitarias de Zaragoza/Ocho y Me dio, 2005) y la tesis doctoral de Eero Jesurun, Representación del inmigrante subsahariano en el cine español contemporáneo. Aproximaciones a la condición poscolonial (Madrid, Uni versidad Carlos III, 2011). enfrentarse a un hermano terrorista dispuesto a aprovechar la ley sobre el arrepentimiento. Hay varios cineastas afrodescendientes activos en la industria italiana, entre los cuales vale la pena señalar por lo menos al director de cortos italo-(afro-)americano Jonas Carpignano, el director-actor de origen tunecino Hedy Krissane (Aspromonte, 2012) y el italo-ghanés Fred Kudjo Kuwornu, que actualmente está trabajando en un documental sobre las condiciones de los actores afrodescendientes (Blaxploitalian-Cent'anni di afrostorie nel cinema italiano).

En Alemania, el talento más significativo es Branwen Okpako, nacida en Lagos (1969) de padre nigeriano y madre galesa, y residente en Berlín desde 1992: activa principalmente en la realización de cortos y documentales, entre ellos el retrato de una excompañera de estudios, cuyo destino es convertirse en la hermana del presidente Barack Obama (Die Geschichte der Auma Obama, 2011). También ha realizado un corto incluido en la antológica Neue bilderSchwarzer Filmschaffender in Deutschland (Berlinale 2007), así como su primer largometraje de ficción, Tal del Ahnunglosen (2003), presentado en Toronto y en Berlín, sobre la búsqueda de identidad de una mujer policía afroalemana crecida en un orfanato ${ }^{41}$.

En España a pesar de la notable producción de largometrajes y documentales sobre el tema de la inmigración desde África ${ }^{42}$, apenas ha emergido una primera ola de directores de segunda generación. Se mantiene por lo tanto aislada la experiencia de Santiago Zannou, hijo de un inmigrante de Benin (a cuyo viaje ha dedicado en 2012 el emotivo documental La puerta de no retorno) y ganador de tres prestigiosos premios Goya por su film de debut El truco del manco (2008), acerca de la amistad de un cantante de hip-hop afectado por una forma de parálisis motora y un amigo afrodescendiente con problemas de drogas, conectados por el sueño de abrir un estudio musical propio. Se apreció menos su segunda obra, Alacrán enamorado (2013), sobre las vivencias de un joven dividido entre la lealtad a un grupo neonazi y el amor por una chica afrodescendiente.

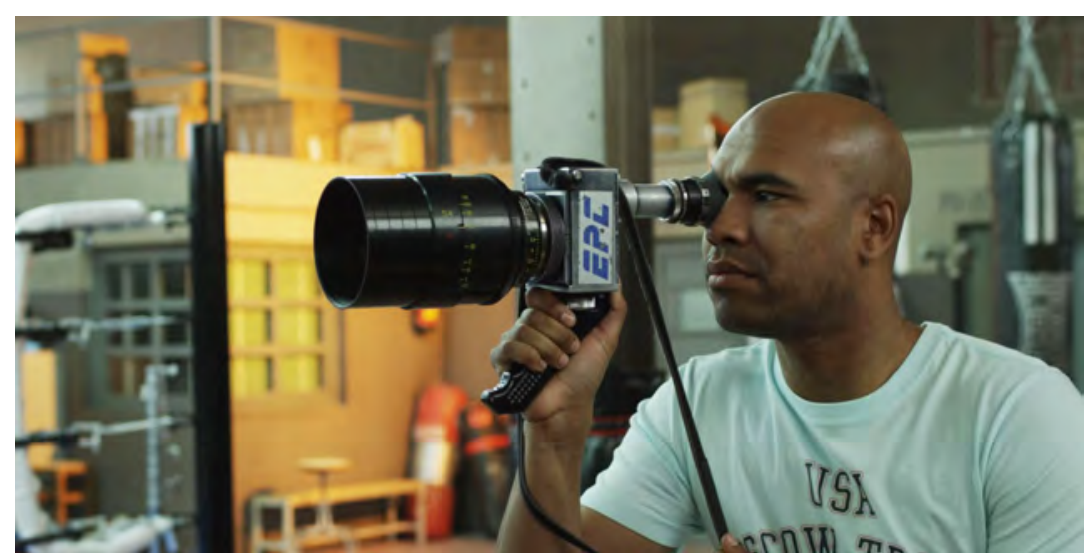

Santiago Zannou. 


\section{Estados Unidos}

De los directores afrodiaspóricos protagonistas de la época de la blaxploitation y de la antagonista Escuela de Los Angeles, pocos quedan en activo: Charles Burnett (1944-) no ha vuelto a recuperar la visibilidad que obtuvo en los años ochenta y noventa y sigue activo sobre todo en la realización de cortos y películas para la televisión. Pero el etíope de nacimiento Haile Gerima (1946-), residente en los Estados Unidos desde 1967, a pesar de los numerosos proyectos que se le han ido quedando en el cajón, consiguió finalmente terminar Teza (2008), presentado y premiado en el Festival de Venecia, una historia de retorno y reconciliación con el país natal, que lo ha ratificado como uno de los grandes autores vivos del cine panafricano. Los años ochenta y noventa habían consagrado el surgimiento de una primera generación de directores-guionistas (Spike Lee, John Singleton, Allen e Albert Hughes, Bill Duke, Carl Franklin, por citar solo algunos nombres) listos para dialogar con las majors, gracias a un nicho de público consistente y un interés creciente por parte del público internacional. El período examinado aquí se ha caracterizado, por un lado, por la consolidación de una producción de tendencial independiente y orientada al público afroamericano, en la tradición del All'Black movie, y por el otro, por el intento de algunos directores de ubicarse en una perspectiva postracial, incluyendo progresivamente historias, personajes e intérpretes blancos y escabulléndose de las trampas del peso de la representación.

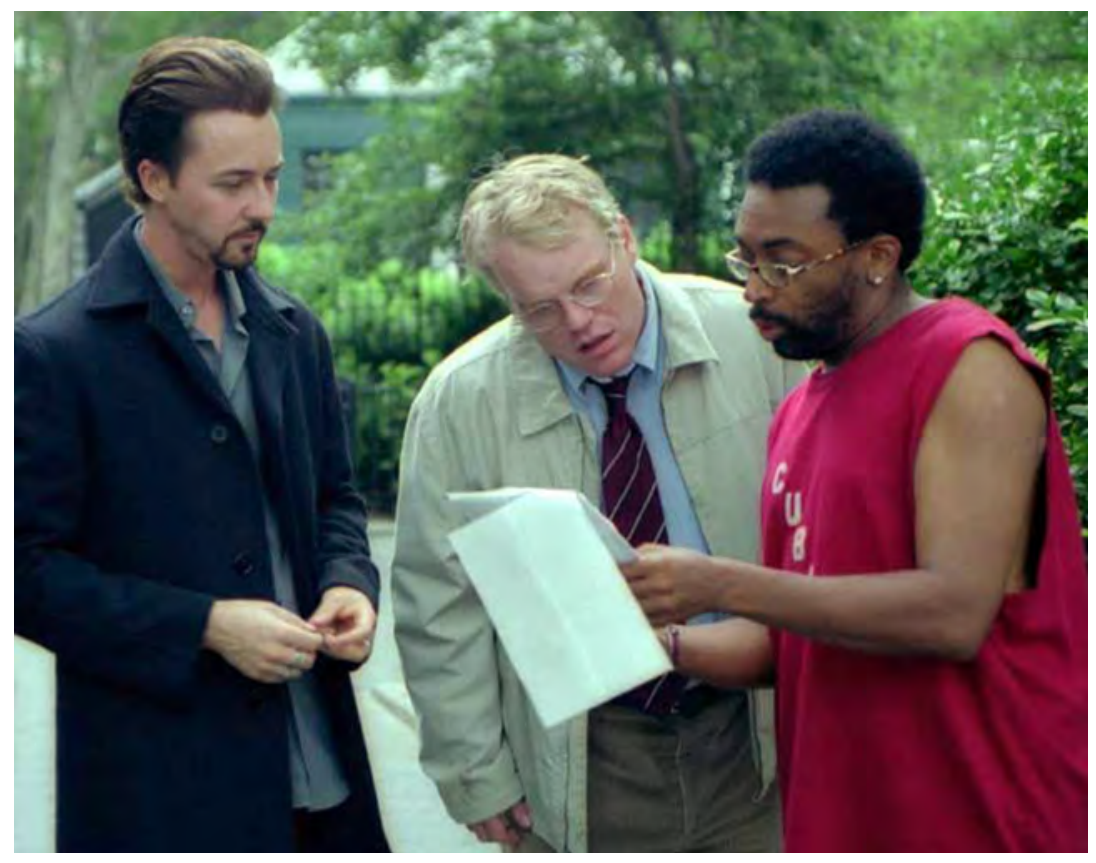

Spike Lee junto a Edward Norton y Philip Seymour Hoffman en el rodaje de La última noche (25th hour, 2002). 


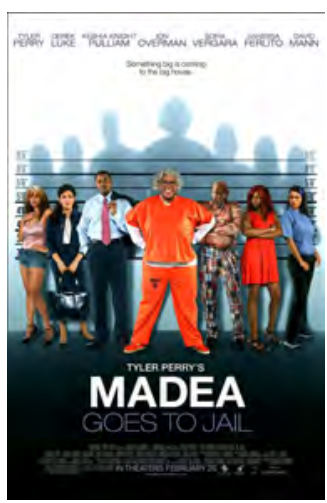

Cartel de Madea goes to jail (Tyler Perry, 2009).

[43] En la misma línea aparece el recorrido de otros directores vinculados al filón de la comedia ligera y black oriented, como Keenen Ivory Wayans, autor del primer Scary Movie, 2000 (obtuvo 278 millones de dólares en todo el mundo) y Malcolm D. Lee (su mayor éxito: El reencuentro [The Best Man Holday, 2013], con 71 millones de dólares de taquilla). Tim Story en cambio oscila entre el blockbuster de éxito universal como Los cuatro fantásticos (Fantastic Four, 330 millones de dólares) y comedias que gustan al público afroamericano, pero con relativamente poca suerte en el extranjero, como la reciente Vaya patrulla (Ride Along, 2014, 153 millones de dólares).
El prolífico Spike Lee (1957-) ha realizado en el período que nos interesa una treintena abundante de cortos, documentales y películas para la televisión, además de ocho largometrajes destinados a la distribución en salas. Lee dio un giro decisivo a su poética con una película clave en la producción contemporánea estadounidense, La última noche (25th hour, 2002), en la que, dejando atrás la subjetividad afroamericanocéntrica de sus inicios y reconectándose con la tradición del Nuevo Hollywood por la capacidad de moverse entre géneros y autorías, independencia productiva y diálogo con el mercado, demostró mejor que otros autores de su generación la capacidad de elaborar el luto del 11 de septiembre. Si bien es cierto que la película claramente más querida tanto por la crítica como por el público estadounidense de la época sigue siendo una heist movie post-racial como Plan oculto (Inside Man, 2006, casi ciento ochenta y cinco millones de dólares acumulados en el mercado mundial, un record absoluto para el director), en la reubicación de Lee fuera de los límites del comunitarismo nacional entrarían también otros dos proyectos menos apreciados como Miracle at St. Anna (2008), inédita coproducción italo-estadounidense sobre el rol que jugaron los Buffalo Soldiers en la liberación de Italia de la ocupación nazi-fascista, y Oldboy (2013), remake de un clásico del cine coreano de Park Chan-Wook.

Mucho más allá en esta carrera por la conquista del público mainstream y postracial han ido John Singleton (A todo gas 2 [2 Fast 2 Furious, 2003]; Cuatro hermanos [Four Brothers, 2005]), F. Gary Gray (The Italian Job, 2003; Un ciudadano ejemplar [Law Abiding Citizen, 2009]), Albert y Allen Hughes (El libro de Eli [The Book of Eli, 2010]) y, sobre todo, Antoine Fuqua (Objetivo: la Casa Blanca [Olympus Has Fallen, 2013]; El protector [The Equalizer, 2014]), que han sabido explotar el estatus de estrella consolidada de actores como Denzel Washington y Jamie Fox. Absolutamente en contra de las tendencias, moviéndose en una perspectiva rigurosamente independiente como productor, director e intérprete de sus propias películas, caracterizadas por una relevante marca serial, el volcánico Tyler Perry (1969-) ha sabido conquistar una sólida popularidad, construida sobre todo en torno a la brillante saga cross-dressing y transmedia de Madea. La saga empezó en 2002 con Madea's Family Reunion, consiguiendo ingresos muy respetables como los más de noventa millones de dólares de Madea Goesto Jail, pero pagándolo con la aversión de la crítica y resultando de escaso atractivo para el público internacional 43 .

Pero este período ha estado marcado por otros dos factores relacionados con el black cinema: el ascenso de un aguerrido grupo de directoras y el de una nueva generación de directores independientes, crecidos a la sombra del Sundance Film Festival.

Si ya en los años noventa habían surgido directoras de talento, activas también en el largometraje, como Julie Dash (Doughters of the Dust, 1991), Darnell Martin (Así me gusta [I Like It Like That, 1994]) y Kasi Lemmons (Eve's Bayou, 1997) en los últimos quince años, la flota de autoras afroamericanas ha crecido considerablemente. Entre ellas, Gina Prince-Bythewood (1969-), que 
lanzada por Lee en el 2000 con su primer largometraje Love and Basketball, ha sabido afinar la capacidad de producir películas que buscan al público mainstream también internacional, pudiendo contar con intérpretes conocidas por el público y dirigiéndose de manera particular a la audiencia femenina (La vida secreta de la abejas [The Secret Life of Bees, 2008]).

Siguiendo la estrella polar de Park City, corazón palpitante del alma más mainstream del cine independiente americano, un cuarteto de autoras que rondan los cuarenta años ha sabido llamar la atención de la crítica estadounidense e internacional. Así, ha dado valor el background de una actriz más bien televisiva ya desde los noventa, Victoria Mahoney, que ha sabido construir pacientemente su debut con Yelling to the Sky (2011), presentado en preestreno mundial en la Berlinale. Más joven pero no con menos determinación, también Dee Rees ha debutado con una película bandera del malestar juvenil femenino, Pariah (2011), lanzada por el Sundance después de que Rees, diplomada en la NYU con Spike Lee, hubiera pasado justamente por el Screening and Directing Lab de Park City, acompañada por un corto a modo de diploma que no era otra cosa que una primera versión de la película con la que iba a debutar. Pero si Mahoney, aun dirigiendo eficazmente a la jovencísima Zoë Kravitz, ha seguido quizás demasiado el modelo de Precious, recuperando también a su protagonista y dejando fría a la crítica, Rees ha conseguido recrear una experiencia de crecimiento y descubrimiento de la sexualidad, ampliando la agenda de la representación del imaginario negro y la experiencia LGTB en una perspectiva intimista y poética, tanto como para poner de acuerdo a la prensa estadounidense.

Bastante apreciada por Sundance fue también Night Catches Us (2011), debut de Tanya Hamilton, jamaicana de origen, que empieza por un tema caliente como el de del movimiento Black Power, para mostrar su posterior caída en esos años setenta, que supusieron el repliegue hacia el individualismo.

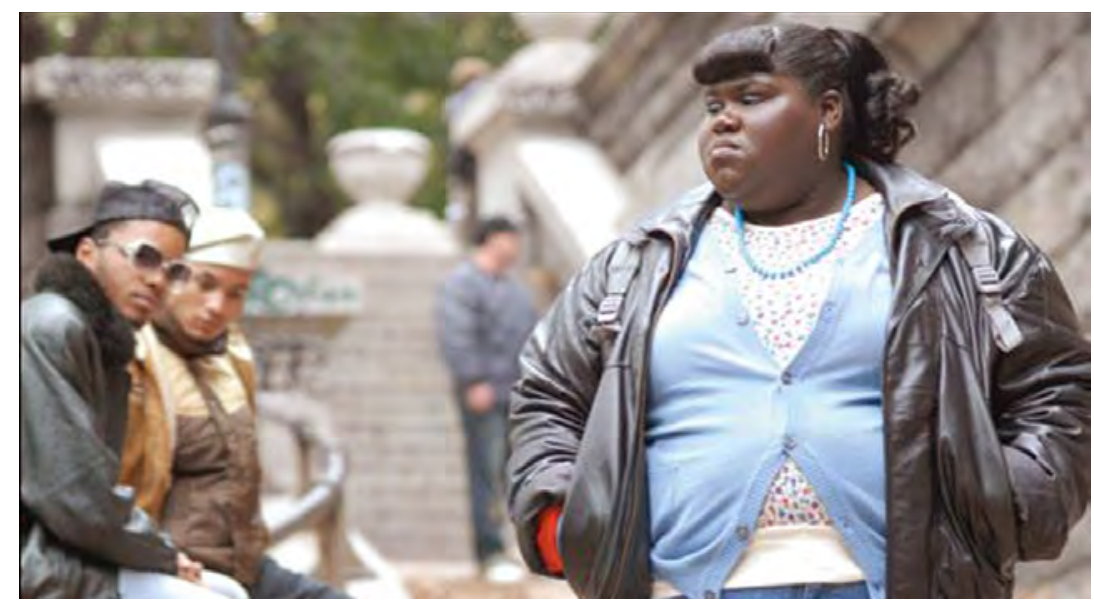

Gabourey Sidibe en Precious (Lee Daniels, 2009). 
Aunque la más cercana a la consagración, en esta fase, sigue siendo Ava DuVernay (1972-) que, reubicándose conscientemente en la tradición de la Escuela de Los Ángeles, apunta a un cine de la exploración interior que trabaja sobre temas universales como la aceptación de la muerte de una persona querida (I Will Follow, 2010) y las condiciones de los presos (Middle of Nowhere, 2012). Ya premiada en Sundance por la dirección de la segunda película, Du Vernay ha sido nominada a los Globos de Oro como mejor directora por Selma (2014), y también en este caso se trata de una primera vez absoluta para una directora afroamericana. La tercera obra de Du Vernay, que reconstruye una de las páginas más densas de la historia del movimiento por los derechos civiles -las marchas que se llevaron a cabo en marzo de 1965 por miles de manifestantes bajo el liderazgo de Martin Luther King-, parece destinada a convertirse en un trampolín ideal para la directora californiana de cuarenta y dos años, quizás también debido a las polémicas que surgieron a causa de no haber sido nominada a los Oscar.

Como anticipábamos, la revelación de Rees, Hamilton y Du Vernay han sido posibles debido a la importancia que ha ido asumiendo el Festival de Sundance para el mercado estadounidense. Este nuevo punto de referencia ha permitido la emergencia de una nueva generación de directores independientes negros a partir del éxito global conseguido por Lee Daniels (1959-) con Precious, vencedor tanto del Premio del Jurado como del Premio del Público en Sundance (además del Premio Especial del Jurado para su protagonista), primera proeza de una afortunada carrera tanto en el circuito de los festivales y de los premios más importantes (incluso el BAFTA y los Oscar, que correspondieron respectivamente al guionista y a la intérprete no profesional Mo'Nique) como en la taquilla (sesenta y tres millones de dólares en todo el mercado). Daniels, que tenía a sus espaldas una ópera prima poco apreciada, ha seguido dando pruebas de discontinuidad, intentando volver la mirada hacia un público postblack, pero atascándose en un fracaso absoluto con El chico del periódico (The Paperboy, 2012, más de doce millones de dólares de presupuesto para poco más de un millón de ingresos en taquilla). Ha sido muy razonada la decisión que lo ha llevado a recuperar antes que nada a su propio público «natural», a través de la prudente elección del argumento y de los intérpretes de una película que ha terminado por convertirse en una especie de manifiesto de la América de Obama, ambiciosamente presentada con su nombre antes del título, The Butler (2013), con el objetivo de consolidar su poder contractual y su llamada comercial, en virtud de la visibilidad conseguida en todo los mercados (ciento setenta y seis millones de dólares recaudados a escala global), aunque la crítica se haya mostrado más bien tibia.

A pesar de la fuerza y la actualidad de su argumento, Fruitvale Station, presentada con éxito en Sundance 2013, y premiada por el jurado y por el público, no ha conseguido el favor del público internacional. Sin embargo, Ryan Coogler (1986-) se ha lanzado a una arriesgada operación de reposicionamiento aceptando la dirección de una suerte de spin off de la saga de Rocky Balboa, 
siempre con Michael B.Jordan como protagonista, con el título de Creed. La leyenda de Rocky (Creed, 2015).

Más subterráneo es el recorrido de dos debutantes indies descubiertos por Sundance entre 2011 y 2012, y que por la elección de los argumentos y el casting, buscan afianzarse ante el público negro. Gun Hill Road (2011), dirigida por Rashaad Ernesto Green (1978-), se ubica en una reconocible tradición de realismo social urbano, y aunque habría tenido muchas posibilidades de mercado, no ha encontrado distribuidores dispuestos a creer en su potencialidad. Ni tampoco An Oversimplification of Her Beauty (2012) dirigido, montado e interpretado por Terenec Nance (1982-), ha conseguido encontrar su público, a pesar de haber seducido a la crítica americana en Sundance, pero ha llamado la atención sobre el talento visionario, incluso egocéntrico, de un joven cineasta con una huella muy personal, del que seguramente seguiremos escuchando hablar. Igual que oiremos hablar del último chico de oro del circuito independiente americano, Justin Simien (1983-) promocionado con una afortunada campaña de Indiegogo y patrocinado por el Festival Tribeca, y saludado finalmente con la acogida triunfal de su debut en Sundance con Querida gente blanca (Dear White People, 2014), una comedia divertida que no se ha reconciliado con los conflictos y privilegios de raza en la América de Obama, ambientada en el exclusivo contexto de un college imaginario dominado por una mayoría de estudiantes blancos pero con un rector negro.

A propósito de independientes descubiertos por Sundance, no se puede cerrar esta sección sin mencionar a un autor transnacional como Andrew Dosunmu: nigeriano de nacimiento, con estudios en Londres y una afortunada carrera como fotógrafo de moda, director de videoclips, documentales y episodios de series. Dosunmu hasta ahora ha realizado dos largometrajes ambientados en una Nueva York apartada y menor, Restless City (2011) y Mother of George (2013). Si ambas buscan equilibrar una escritura audiovisual fuertemente agresiva -caracterizada por planos largos, uso de la cámara lenta y el ajuste en marcha del enfoque- con un material narrativo dramático, el segundo largometraje (retrato de una mujer obsesionada por tener que entregar a su hijo al marido) delinea perfiles psicológicos más complejos y profundos, tanto que ha conseguido poner de acuerdo a gran parte de la crítica estadounidense.

\section{Las otras Américas}

La escena del cine afrodiaspórico canadiense aún aparece fragmentada y dispersa. Clement Virgo, de cuarenta y nueve años, de origen jamaicano, ha tenido hasta ahora buenas oportunidades de lanzamiento internacional que tal vez no haya sabido explotar mejor. Lie with Me. El diario íntimo de Leila (Lie with $\mathrm{Me}$ ) presentada en Toronto en 2005 sobre la base de una lógica rigurosamente no nacionalista (la historia era la de un amour fou entre dos jóvenes blancos) y un buen ojo para utilizar prudentemente el factor erótico, era un film intere- 
[44] Regis Dubois, «Le cinéma noir de France» en Les Noirs dans le cinéma français. Images et imaginaires d'hier et d'aujord'hui (s.l., The Book Edition, 2012), pp. 81-95. sante sobre todo para una audiencia atenta a las producciones independientes y, de hecho, llegó a varios mercados europeos. Último asalto (Poor Boy's Game, 2007), exhibida en dos importantes plazas como Toronto y Berlín, está mayormente en sintonía con la tradición del cine orientado al público negro, gracias a una historia que trabaja los temas de la marginación social, el racismo y la redención a través del deporte, dejando aparte el atractivo que garantiza el rostro de Danny Glover. Pese a todo ello, no ha encontrado distribución. Después de algunas series de televisión, Virgo ha vuelto a trabajar en un prometedor proyecto de serie televisiva (The Book of Negroes), muy similar al filón de las slave movie que ha vuelto con los éxitos de Tarantino y McQueen.

También el escritor de sesenta y un años Dany Laferrière proviene del Caribe, nacido en Haití y refugiado en Montreal en 1976 a causa de su actividad como periodista disidente contra el régimen de Duvalier. Muchos de sus textos han sido objeto de adaptaciones cinematográficas, empezando por su primer best seller Cómo hacer el amor con un negro sin cansarse (Comment faire l'amour avec un négre sans se fatiguer, Jacques W.Benoit, 1989). Laferrière intentó también el camino del debut detrás de la cámara en 2004 con una comedia diaspórica divertida pero elaborada a partir de estereotipos ya gastados, Comment conquérir l'Amerique (2004).

Dos jóvenes talentos diaspóricos de origen caribeño como Dawn Wilkinson y Sudz Sutherland, debutaron la primera con Devotion (2005) y el segundo incluso antes con Love, Sex and Eating the Bones (2003), presentado en Toronto. Aun siendo muy conocidos en la red de festivales black y muy activos en la dirección en televisión, esperan todavía una oportunidad de difusión entre un público más grande e internacional.

Si nos movemos desde América Central, al Caribe o a Sudamérica, la situación se vuelve más difusa y compleja de interpretar, por lo cual resulta difícil articular reflexiones que puedan generalizarse. La percepción, aquí también, es la de que es un mercado disperso, aún sin organizar, con potencialidades de desarrollo que aún no se han realizado, sin que por ello falte el talento.

En el área de las Antillas, paradójicamente las experiencias más visibles vienen de un contexto no estatal, como el de los tradicionalmente llamados DOM-TOM: departamentos y territorios del outre-mer francés. Directores como Christian Lara (1939-), Euzhan Palcy (1958-), Guy Deslauriers (1958-), Lucien Jean-Baptiste (1964-), Christian Grandman (1969-), Jean-Claude Flamand Barny y Marc Barrat, por citar solo algunos de los directores nacidos en las Antillas Francesas cuyas obras se desarrollan en un arco temporal de varias décadas -desde el final de los años setenta en adelante (Coco la fleur, candidat, debut de Lara, es de 1979)-, se encuadran en un horizonte intelectual común, como expresión de un cine negro francés ${ }^{44}$. Este, después de algunas experiencias pioneras anteriores especialmente desde finales de los años noventa, se ha manifestado en tres géneros -la película histórica, el drama social y la comedia- dentro de un contexto que comprende producciones dirigidas tanto a las salas como a la pequeña pantalla. Parece lógico en este caso encontrar una sus- 
tancial continuidad entre 1802, l'epopée guadeloupéenne (Lara, 2005), Aliker (Deslauriers, 2009) y algunos ejemplos anteriores de películas históricas, si se interpretan a partir de una política cultural nacionalista, que tiende a recuperar para el debate público figuras históricas de militantes subalternos y anticoloniales, y que, también por esta razón, se encuentra con problemas de censura del mercado. A esta producción la acompañan películas como Tèt Grenné (Grandmann, 2001) o Nèg maron (Barny, 2004), que enmarcan las problemáticas experiencias de jóvenes de origen antillano que viven en el interior de los barrios en riesgo de exclusión social de las metrópolis francesas; y, en el caso de Orpailleur (Barrat, 2008) y del citado Le Bonheur de Elza, la dificultad de la vuelta a países vistos con una mirada muy alejada del imaginario turístico. En la película de Monpierre, se asoma, filtrado por una atención totalmente femenina, íntima y personal a las relaciones intergeneracionales, el tema universal de la búsqueda del padre. Volvemos a encontrarlo junto a una reflexión más amarga y lúcida sobre el peso de las decisiones políticas que pueden separar a padres e hijos (aquí, a un hijo disidente de un padre oficial de los Tonton Macoute), en la intensa Woch nansolei/Stones in the sun (2012), debut de la haitiana Patricia Benoit, premiada por el jurado del Tribeca.

A partir del modelo de Antilles sur Seine (Pascal Legitimus, 2000), «manifiesto por un cine negro francés para el gran público y sin complejos» ${ }^{45}$, la comedia acentuada (como diría Naficy) de Lucien Baptiste La premiére étoile (2009), además de estar construida para dotar de valor al talento de muchos actores y actrices afrodescendientes franceses, obligados durante largos períodos a papeles secundarios, ha tenido una buena acogida de público (1,6 millones de euros).

Por otro lado, incluso saliendo del ámbito del mercado francés, no sorprenderá encontrar entre los cineastas más queridos por los jurados de los festivales panafricanos al veterano haitiano Arnold Antonin, nacido en Puerto Príncipe en 1942, autor de documentales sociales pero también de películas de ficción entre lo cómico y lo edificante como Le Président a-t-il le Sida? (2007), sobre las desventuras de un cantante de extracción popular, mujeriego y supersticioso, que se descubre enfermo de VIH en la cumbre del triunfo y Les amours d'un zombie (2011), relato metafórico acerca del ascenso social de un zombi cortejado por la política. En otro registro distinto, aun quedándose dentro del imaginario haitiano profundo, hay que situar el debut, visualmente fulgurante y molesto, del americano de origen haitiano Michelange Quay (1947): Mange, ceci est mon corps (2011) juego con los roles de ama y esclavo, ambientado en un horizonte temporal suspendido entre el orden colonial y el neocolonial.

Pero ni Antonin ni Quay pueden gozar de la atención que el haitiano Raoul Peck (1953-) ha sabido alcanzar en una carrera de más de treinta años, gracias a su reconocible autoría y también a su capacidad para trabajar en proyectos de coproducción que movilizan fondos estadounidenses y franceses, con destino mayoritariamente televisivo. Tal es el caso de Sometimes in April (2005), una de

[45] Dubois, Les Noirs dans le cinéma français, p. 90. 
las primeras y más complejas relecturas del genocidio ruandés, realizada con un casting afrodiaspórico internacional que incluía a Idris Elba; y Moloch tropical (2009), retrato del ocaso de un dictador haitiano imaginario, interpretado por el intenso Zinedine Soulem.

El jamaicano de nacimiento Alrick Brown se mueve entre los intersticios del mercado y del imaginario. Su opera prima Kinyarwanda, seleccionada en 2011 por Sundance y premiada por el público, reinterpreta a su vez la tragedia el genocidio ruandés con una sensibilidad al mismo tiempo íntima y controlada, con capacidad para ser un relato polifónico y narrativamente intrigante, pero no

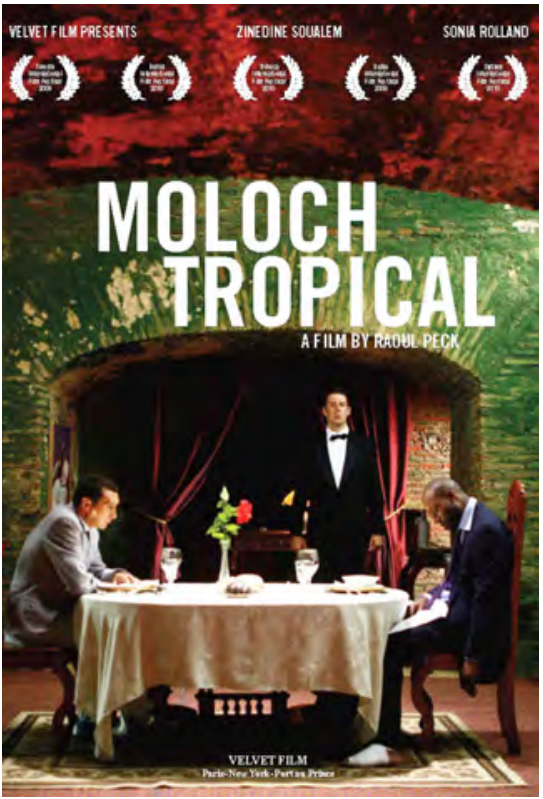

Cartel de Moloch tropical (Raoul Peck, 2009). sensacionalista, sobre la base de experiencias reales.

En una cinematografía tan poco visible en los mercados mundiales como es la colombiana, uno de los pocos títulos que han llegado a atraer cierta atención de la crítica internacional ha sido justamente el debut del director afrodiaspórico Jhonny Hendrix Hinestro za (1975-), Chocó, presentado en la Berlinale. Se trata de un doliente apólogo sobre una condición femenina humillada y ofendida pero lista para la rebelión y la redención, en un contexto socio-ambiental marcado por el contraste entre la pobreza, la explotación y la desgarradora belleza de los paisajes.

En cuanto a la situación de los negros en el cine brasileño de los últimos quince años, solo podemos dar cuenta brevemente de una problemática que merecería unas premisas y una precisión mucho más articuladas, teniendo en cuenta que la identidad negra es parte profunda de la cultura y de la imagen

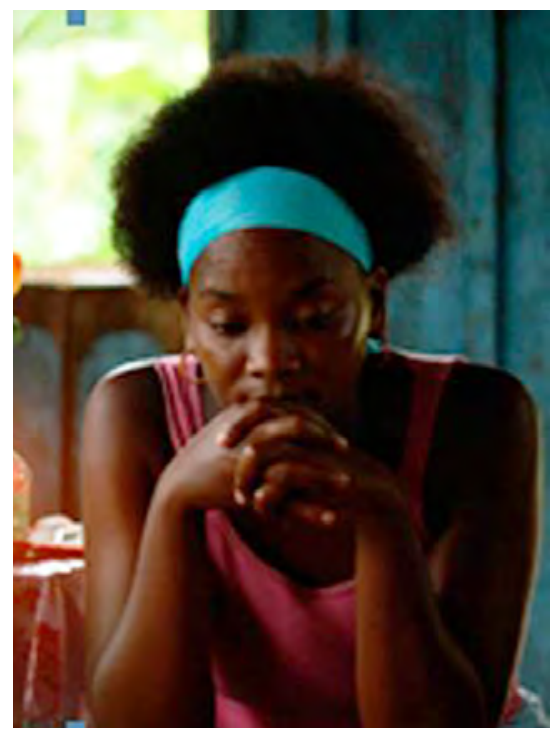

Fotograma de Chocó (Jhonny Hendrix Hinestroza, 2012). 
de Brasil ${ }^{46}$. En tiempos poco suspicaces, Robert Stam nos ponía sobre aviso frente al «peligro de que la celebración de la contribución de la cultura afrobrasileña al cine brasileño podría implicar una aprobación de la supuesta “democracia racial” de Brasil» recordando al mismo tiempo que Brasil es «la nación negra más grande fuera de África con al menos setenta millones de ciudadanos que descienden, de una manera u otra, de los esclavos traídos de África» ${ }^{47}$. Más recientemente, Stam y Shohat han subrayado el valor pionero de iniciativas como las del Black Experimental Theatre (1944-68) y de la revista Quilombo (1948-50), a través de las cuales el actor, dramaturgo y poeta Abdias do Nascimiento luchó porque se valorase a los actores afrodescendientes, en el interior de una industria del espectáculo condescendiente con la práctica del blackface ${ }^{48}$.

No obstante las evidentes potencialidades, y la presencia de un elenco de actores afrodescendientes de gran valor y con personalidades de absoluta relevancia como Grande Otelo (1915-93), Zósimo Bulbul (1937-2013), Antônio Pitanga (1939-), Zezé Motta (1944-), a los que se puede sumar la última estrella negra del star system carioca, el bahiano Lázaro Ramos (1968-), aún estamos lejos de ver en Brasil una experiencia de cine afrodescendiente aunque solo sea remotamente comparable con la que se da en Estados Unidos.

Hay, sin embargo, diferentes directores en activo como Joel Zito Araújo (1954-) y Jeferson De (1969-), Rogério De Moura (1970-) que, aun habiendo realizado solo una película, han dado que hablar en Brasil y a los que se puede augurar buenas expectativas de futuro. De los tres debuts, el más aclamado y premiado por la crítica ha sido seguramente Bróder (De, 2009), presentado en la Berlinale de 2010. Es un guion desarrollado en el Sundance Film Lab, que trata una historia de amistad y malestar social ambientada en una favela de São Paulo, con un atento desarrollo psicológico de los personajes y una escritura antiexpresionista, lejos de cualquier compromiso con olor de slumsploitation. Director de cuatro cortos, activo en diferentes frentes, entre ellos la web (jeferson.blogspot.it), De también es autor de un conocido manifiesto por un cine afrobrasileño: o Dogma Feijoada, publicado originalmente en noviembre de 1999, como expresión de un grupo (Cinema Feijoada) que comprendía a otros cineastas afrodescendientes brasileños (Noel Carvalho, Billy Castilho, Rogério de Moura, Ari Candido Fernandez, Daniel Santiago), a partir de una investigación conducida por el mismo autor en el ámbito de un curso de cine en la Universidad de São Paulo y desarrollado en un estudio más articulado en $2005^{49}$. El manifiesto suscitó cierto debate en el seno del cine brasileño, produciendo como respuesta un nuevo documento, el Manifiesto do Recife (2001), elaborado en el curso del Festival de cine de Recife, para favorecer la diversidad cultural en la industria cinematográfica y reclamar una estética más inclusiva y respetuosa con el pluralismo étnico, regional y religioso de la sociedad brasileña, que han firmado numerosos cineastas, entre los cuales están los ya citados Araújo, Bulbul y Pitanga.
[46] Para quien quiera profundizar sobre la cuestión: Gizelda Maria Alves Hengstl, Das neue Cinema Negro in Brasilien (Marburg, Phillips-Universität Marburg, 2014), <http://archiv. ub.uni-marburg.de/diss/z2014/ 0692/pdf/dgah.pdf>, Joao Carlos Rodrigues, $O$ negro brasileiro e o cinema (Rio de Janeiro, Globo, 1988), Robert Stam, Tropical Multiculturalism. A Comparative History of Race in Brazilian Cinema and Culture (Durham, Duke University Press, 1997).

[47] Robert Stam, «Samba, Candomblé, Quilombo. Black Performance and Brazilian Cinema»en Michael T. Martin (dir.), Cinemas of Black Diaspora, p. 282.

[48] Robert Stam, Ella Shohat, Race in Translation, p. 175.

[49] Los siete puntos del manifiesto de De son los siguientes: «1- La película tiene que estar dirigida por un director brasileño; 2-El protagonista tiene que ser negro; 3-El argumento de la película tiene que relacionarse con la cultura negra brasileña; 4-La película tiene que tener un calendario factible; 5-Personajes estereotipados negros (o no) están excluidos; 6-El guion tendrá que privilegiar al negro brasileño común; 7-Super héroes y villanos tendrán que evitarse». Jeferson De, Dogma Feijoada. $O$ cinema negro brasileiro (São Paulo, Imprensa Oficial, 2005), <http: //livraria.imprensaoficial.com.br /media/ebooks/12.0.813.132. pdf>, p. 96. 
Justamente en esa edición del festival, se presentó el documental Anegaçap do Brasil (2000), en el cual Araújo pasa revista a los estereotipos más recurrentes a la hora de construir los personajes negros en el imaginario fílmico nacional. Araújo, por lo general documentalista, es también autor de un llamativo largometraje con el que debutó, interesado en hacer emerger el libre albedrío del sujeto femenino: Filhas do Vento (2004), sobre la relación de amor y odio que vincula a dos hermanas cuyo destino es muy diferente del de su padre, cuya muerte las hace reencontrarse después de décadas de separación. Hay que recordar además que uno de los talentos reconocidos más significativos del cine brasileño, Karim Aïnouz, autor de una ópera prima muy apreciada en todo el mundo como Madame Satã (2002), sobre las aventuras de la homónima drag queen capoerista (1900-76), intepretada con admirable pathos por Lázaro Ramos, y de otras tres películas que han gozado de un buen eco en los mayores festivales internacionales, alardea de orígenes afrodiaspóricos, ya que nació en Fortaleza en 1966, de madre brasileña y padre argelino.

Este movimiento por el desarrollo de un cine afrobrasileño empieza a contar también con diferentes eventos festivaleros, distribuidos por el territorio nacional y extranjero ${ }^{50}$. Igualmente, hay ya en la rampa de lanzamiento para su primer largometraje varios talentos que han dado buenas sensaciones en el cortometraje, como Danddara (1968-) ${ }^{51}$.

\section{Conclusiones}

El cine diaspórico independiente es una realidad en expansión, que se va consolidando con modalidades muy diferentes según los contextos nacionales. El éxito creciente de las estrellas negras de diferente origen como Denzel Wa shington, Idris Elba, u Omar Sy, junto con la afirmación en los Oscar del Black British Steve Mcqueen, está facilitando la articulación de un nicho de público transnacional, formado mayoritariamente por jóvenes afrodescendientes cada vez más conscientes y deseosos de verse representados por personajes negros en papeles importantes, héroes o no. Naturalmente el mercado, como sucedió con la parábola de la Blaxploitation en los años setenta, siempre está dispuesto a comercializar los márgenes, según expresión de Graham Huggan, explotando y quemando el talento de cineastas afrodescendientes, sin alterar los equilibrios

[50] Entre las varias iniciativas, señalo el Festival Internacional de Cine Negro, surgido en el 2003 en São Paulo y la reseña Cinema negro, creada en Berlín en 2005 (http:// www.cinemanegro.de).

[51] Dos cortometrajes de Danddara se pueden ver en su página de Vimeo:

(http://vimeo.com/danddara). profundos de un imaginario fílmico global que sigue sustancialmente dominado por un orden eurocéntrico y por un privilegio blanco normalizador y, por lo tanto, invisible a las mayorías. No obstante, desde los Estados Unidos hasta Europa, pasando por Brasil, somos testigos de la emergencia de una sensibilidad proactiva, flexible y pragmática, por parte de los directores afrodescendientes, que se mueven con diferentes estrategias de política identitaria y de relación con la industria, persiguiendo los mismos objetivos de empoderamiento. La referencia a la agenda nacionalista e identitaria, cuando está presente de manera marcada, sí que tiende a construir una relación privilegiada con un 
público de referencia afrodescendiente, incluso transnacional, pero intenta incidir también en el imaginario y en el mercado mainstream, intentando evitar las trampas de un identitarismo exclusivo y autoguetizante, consciente de las fuertes desigualdades en el orden simbólico y material que la crisis económica global en curso ha agravado, haciendo emerger la coexistencia de viejas y nuevas configuraciones discursivas transnacionales (raza, clase, género, orientación sexual). Pesa en algunos, especialmente en los pertenecientes a la generación que se formó en los ochenta (Spike Lee, Steve McQueen, Abdellatif Kechiche, por citar solo algunos nombres), el intento de desmarcarse de la hipoteca invalidante del peso de la representación que sigue tocando a los directores afrodescendientes, con la complicidad de una crítica cinematográfica que -si bien cada vez menos audible en la época del ocaso del cine como forma principal de narración de lo contemporáneo, y de la paradójica y contemporánea proliferación en la red de discursos públicos sobre cine-, sigue interpretando la experiencia de los directores afrodiaspóricos desde una perspectiva discontinua, excepcional, como expresión de un cada vez más fantasmal grupo de referencia.

La asamblea de la ONU, con la resolución 68/237 ha proclamado el 201524 como el Decenio Universal de los Pueblos de origen africano, promoviendo un programa de iniciativas que insisten sobre tres principios -reconocimiento, justicia y desarrollo-, en continuidad con lo que se estableció en la conferencia de Dubai en 2001. Sería de esperar que el programa incluyera también el eje de la cultura, y en particular de las narraciones audiovisuales, como horizonte operativo, en el plano de la industria y del imaginario, pero sin caer en las trampas esencialistas de una visión preservacionista y discontinuista de la diversidad cultural, que ya denunció en su tiempo Amselle5².

\section{Traducción del italiano: Arturo Tena}

\section{BIBLIOGRAFÍA}

Alves Hengslt, Gizelda Maria, Das neue Cinema Negro in Brasilien (Marburg, PhillipsUniversität Marburg, 2014). Disponible en: http://archiv.ub.uni-marburg.de /diss/z2014/o692/pdf/dgah.pdf

Amselle, Jean-Loup, Logiques métisses. Anthropologie de l'identité en Afrique et ailleurs (Paris, Payot, 1990).

APPAUDRAI, Arjun, Modernity at Large: Cultural Dimensions of Globalization (Minneapolis, University of Minnesota Press, 1996).

BARLET, Olivier, Les cinémas d'Afrique des années 20oo. Perspectives critiques (Paris, L'Harmattan, 2012).

Bonilla Silva, Eduardo, Racism without Racists: Color-Blind Racism and the Persistence of Racial Inequality in America, $4^{\text {th }}$ ed. (Plymouth, Rowman \& Littlefield Publishers, 2013).
[52] He podido detenerme en la cuestión en un texto al que reenvío. Leonardo De Franceschi, «Io sono là-bas. Prove tecniche di liberazione dell'immaginario, dentro e fuori la fortezza Europa», Cinemafrica - Africa e diaspore nel cinema, 29 de noviembre de 2011 (http: //www.cinemafrica.org/page. php?article1210). 
Bourne, Stephen, Black in the British Frame. The Black Experience in British Film and Television (London and New York, Continuum, 2011).

Clifford, James, Routes. Travel and Translation in the Late Twentieth Century (Cambridge, MA, Harvard University Press, 1997).

DE Jeferson, Dogma Feijoada. O cinema negro brasileiro (São Paulo, Imprensa Oficial, 2005). Disponible en: http://livraria.imprensaoficial.com.br/media/ebooks/12.o. 813.132.pdf.

De Francheschi, Leonardo (dir.), L’Africa in Italia. Per una controstoria postcoloniale del cinema italiano (Roma, Aracne editrice, 2013).

De Francheschi, Leonardo, «Io sono là-bas. Prove tecniche di liberazione dell'immaginario, dentro e fuori la fortezza Europa», (Cinemafrica - Africa e diaspore nel cinema, 29 novembre 2011). Disponible en: http://www.cinemafrica.org/page. php?article1210.

Delippe, Dennis, Protesting Affirmative Action: The Struggle over Equality after the Civil Rights Revolution (Baltimore, The Johns Hopkins University Press, 2012).

DENTON, Nadia, The Black British Filmmaker's Guide to Success (s.l., s.e., 2011).

-, The Nigerian Filmmaker's Guide to Success: Beyond Nollywood (s.l., s.e., 2014).

Diawara, Manthia (dir.), Black American Cinema (New York and London, Routledge, 1993).

Dubois, Regis, Les Noirs dans le cinéma français. Images et imaginaires d'hier et d'aujourd'hui (s.l., TheBookEdition, 2012).

Gabriel, Teshome H., Third Cinema in the Third World: The Aesthetics of Liberation (Ann Arbor, UMI Research Press, 1982).

HigbeE, Will, Lim, Song Hwee, «Concepts of Transnational Cinema: Towards a Critical Transnationalism in Film Studies» (Transnational Cinemas, vol. 1, issue 1, 2010).

JEDLOWski, Alessandro, Nollywood. L’industria video nigeriana e le sue diramazioni (Napoli, Liguori, in corso di pubblicazione).

JESURUn, Eero, Representación del inmigrante subsahariano en el cine español contemporaneo. Approximaciones a la condición poscolonial (Madrid, Universidad Carlos III, 2011). Disponible en: http://e-archivo.uc3m.es/bitstream/handle/ 10016/13767/Tesis\%2oDoctoral\%20Eero\%20Jesurun.pdf?sequence=1.

Krings, Matthias; Onokoome Okome (dir.), Global Nollywood. The Transnational Dimensions of an African Video Film Industry (Indiana University Press, Bloomington, 2013).

Ledwidge, Mark, Verney, Kevern, PARMar, Inderjeet (dir.), Barack Obama and the Myth of a Post-Racial America (New York and London, Routledge, 2013).

Marks, Laura, The Skin of Film: Intercultural Cinema, Embodiment, and the Senses (Durham/London, Duke University Press, 2000).

MARTin, Michael T., «Framing the 'Black' in Black Diasporic Cinemas», en Michael T. Martin (dir.), Cinemas of Black Diaspora. Diversity, Dependence and Oppositionality (Detroit, Wayne State University Press, 1995).

Мвемве, Achille, Sortir de la longue nuit. Essai sur l'Afrique décolonisée (Paris, Éditions La Découverte, 2010).

Mellino, Miguel, La critica postcoloniale. Decolonizzazione, capitalismo e cosmopolitismo nei postcolonial studies, (Roma, Meltemi, 2005).

MERCER, Kobena, «Black Art and the Burden of Representation» (Third Text, vol. 4, issue 10, 1990), pp. 61-78. 
Morley, David, KuAn-Hsing, Chen (dir.), Stuart Hall: Critical Dialogues in Cultural Studies (New York, Routledge, 1996).

NAFicy, Hamid, An Accented Cinema: Exilic and Diasporic Filmmaking (Princeton, NJ/Oxford, Princeton University Press, 2001).

Petry, Sheila J., Contact Zones. Memory, Origin, and Discourses in Black Diasporic Cinema (Detroit, Wayne State University Press, 2008).

Quayson, Ato, Daswani, Girish (dir.), A Companion to Diaspora and Transnationalism (Malden/Oxford/Chicester, Wiley-Blackwell, 2013).

Rodrigues, Joao Carlos, O negro brasileiro e o cinema (Rio de Janeiro, Globo, 1988).

SANTAOLALla, Isabel, Los «Otros». Etnicidad y «raza» en el cine español contemporáneo (Zaragoza/Madrid, Prensas Universitarias de Zaragoza/Ocho y Medio, 2005).

SELASI, Taiye, «Bye-Bye Babar» (The Lip, 3 March 2005). Disponible en: http: //thelip.robertsharp.co.uk/?p=76.

Sнонат, Ella, Stam, Robert, Unthinking Eurocentrism. Multiculturalism and the Media (New York/London, Routledge, 1994).

Sim, Gerald, The Subject of Film and Race: Retheorizing Politics, Ideology, and Cinema (New York/London/New Delhi, Sidney, Bloomsbury Academic, 2014).

Stam, Robert, Tropical Multiculturalism. A Comparative History of Race in Brazilian Cinema and Culture (Durham, Duke University Press, 1997).

Stam, Robert, Sнонат, Ella, Race in Translation: Culture Wars around the Postcolonial Atlantic (New York and London, New York University Press, 2012).

TcheuyaP, Alexie, Postnationalist African Cinemas (Manchester, Manchester University Press, 2011).

Tessler, Michael, SEARs, David O., Obama's Race: The 2008 Election and the Dream of a Post-Racial America (Chicago, The University of Chicago Press, 2008). 